\section{(D) Check for updates}

Cite this: Polym. Chem., 2020, 11 2274

Received 27th December 2019, Accepted 6th February 2020

DOI: 10.1039/c9py01937e rsc.li/polymers

\title{
Polymer mechanochemistry-enabled pericyclic reactions
}

\author{
Emilia Izak-Nau, (ID $\dagger^{a}$ Davide Campagna, (ID) $\dagger^{\mathrm{a}, \mathrm{b}}$ Christoph Baumann (ID $\dagger^{\mathrm{a}, \mathrm{b}}$ and \\ Robert Göstl (D)*a
}

\begin{abstract}
Over the past decades, it became clear that next to heat and light, pericyclic reactions can be induced mechanochemically when the reacting motifs are embedded as latent force-responsive groups (mechanophores) into polymer architectures. Not only does this enable a variety of functions and applications on a material level, but moreover grants access to symmetry-forbidden reaction products with respect to the Woodward-Hoffmann rules. The latter indicates that polymer mechanochemistry follows its own set of rules that, however, regarding underlying mechanisms and design rationales is far from being holistically understood. Here we review the existing body of literature and identify common structural features and substitution prerequisites to the polymer framework shining light on the differences between polymer mechanochemical pericyclic reactions and their traditional counterparts. By this, we believe to contribute to the major challenge of not only retrospectively describing force-induced reactivity but eventually finding a common molecular design guideline.
\end{abstract}

\section{Introduction}

The use of mechanical force to induce chemical bond transformations in polymers enables reactions that cannot proceed using other, more established physical stimuli, such as light and heat. ${ }^{1}$ Unlike heat, force is a vector quantity, i.e. it is intrinsically directional with regard to bond orientation. Moreover and contrarily to light, force-controlled reactions proceed on the ground state potential energy surface (PES). ${ }^{2}$ Reductively, force acting on molecules can be interpreted as alteration of the geometries and distances of the atoms participating in the force-controlled chemical reaction - comparable to Hammond's postulate of transition state theory. ${ }^{3}$ While force and pressure have been applied to steer chemical reactions for millennia, e.g. in milling processes, ${ }^{4-6}$ the relatively young field of polymer mechanochemistry allows to exert better control over the applied force to the respective participating reactants. Whereas milling acts on the reactants omnidirectionally by compression and impact, polymer mechanochemistry relies on the extension of macromolecular termini that are substituted to individually defined positions of the reacting molecular motif - the mechanophore. This allows precise localization of the force and hence introduces a sense

\footnotetext{
${ }^{a}$ DWI - Leibniz Institute for Interactive Materials, Forckenbeckstr. 50, 52056 Aachen, Germany.E-mail: goestl@dwi.rwth-aachen.de

${ }^{b}$ Institute for Technical and Macromolecular Chemistry, RWTH Aachen University, Worringerweg 1, 52074 Aachen, Germany

$\dagger$ These authors contributed equally to this work.
}

of directionality by 'force-coupling' certain bonds within the mechanophore. ${ }^{7}$ In consequence, most reactions in polymer mechanochemistry known today rely on the extension-induced selective bond scission as initial step of the mechanochemical reaction. Notably, this paradigm might be challenged in the future with the discovery of 'molecular anvils' that can exert compressive forces on molecules in a directional fashion, too. ${ }^{8}$ However, polymer mechanochemistry is more than a collection of destructive processes as the downstream formation of new bonds can be achieved, e.g. by the force-activation of latent catalysts. $^{9}$

The force-induced bond-scission along the path of hundreds of covalent bonds within the mechanophore-centred polymer is a competition between these bonds. Hence, selectivity regarding the identity of the bond that cleaves can only be achieved by tailor making the mechanophore such that it exhibits a higher force-dependent scission rate than the polymer backbone or other functional moieties. While the electronic structures of the reactants remain widely unaffected by force when compared to light and heat, atomic motion along the reaction coordinate is altered by molecular stress and strain. ${ }^{10}$ This renders the design process of new mechanophores unintuitive and hence is generally carried out by educated guessing while building on already established motifs. ${ }^{11}$ Thermal bond dissociation energies (BDEs) are used as a first estimation to assess the propensity of a covalent bond to undergo scission under force. ${ }^{12}$ This approach is intrinsically flawed as it assumes identical reaction pathways along the PES for thermal and mechanochemical reactions, ${ }^{13}$ but has yielded reasonable 
successes in the past. A BDE of about $300 \mathrm{~kJ} \mathrm{~mol}^{-1}$ (72 kcal $\mathrm{mol}^{-1}$ ) can be considered mechanochemically promising ${ }^{14}$ (the BDE of a C-C bond is ca. $360 \mathrm{~kJ} \mathrm{~mol}^{-1}\left(86 \mathrm{kcal} \mathrm{mol}^{-1}\right)$, for perspective).

A plethora of mechanochemically labile bonds exist that can be cleaved by various forms of force. However, a strikingly large amount of these mechanophores relies on motifs that undergo pericyclic reactions, more precisely those pericyclic reactions that lead to bond dissociation. This is initially surprising as, e.g. cycloeliminations, involve the dissociation of two covalent bonds and intuitively one could assume that this would be mechanochemically more difficult than the dissociation of a single covalent bond elsewhere in the macromolecule. Yet, many papers have been published over the last decades indicating that dissociative pericyclic reactions are indeed selectively accessible by mechanical force, though they might not always follow the thermally or photochemically established mechanisms and thus occasionally oppose the Woodward-Hoffmann (WH) rules. ${ }^{15}$ While excellent reviews are available focusing on the functions and applications that can be realized by employing mechanophores in materials as well as their interpretation, ${ }^{9,16-23}$ we here explicitly and comprehensibly review all polymer mechanochemical transformations based on pericyclic and pseudopericyclic reactions on the mechanophore level in relation to their molecular designs.

\section{Cycloelimination of $[2+2]$ cycloadducts}

\section{Four-membered carbocycles}

The formation of strained cyclic structures is an established strategy to reduce the internal stability of molecules. Cyclobutane is one of the simplest strained cycles as a fourmembered ring bearing only saturated carbon atoms. As cyclobutane can be formally seen as the $[2+2]$ cycloadduct of two alkenes, subjecting it to a force-induced cycloelimination reaction was considered promising and subsequently achieved (Scheme 1). ${ }^{24-26}$

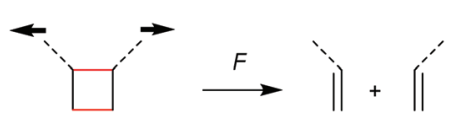

Scheme 1 General scheme of the bonds involved in the cycloelimination of a $[2+2]$ cycloadduct. Attachments to polymer framework are represented as dashed bonds, application and direction of force in bold arrows, reacting bonds in red - here and throughout the manuscript.
In 2010, Moore and co-workers synthesized the first mechanophore based on the cyclobutane motif which showed mechanochemical activity in solution exerted by ultrasonication. $^{24}$ A dicyano-substituted cyclobutane ring (Scheme 2) was integrated into the centre of linear poly(methyl acrylate) (PMA) chains. The mechanochemical activity of the motif was qualitatively confirmed by postfunctionalization with 9-(methylaminomethyl)anthracene (MAMA) that reacted with the mechanochemically generated $\alpha, \beta$-unsaturated system via Michael-type addition. UV-Vis absorption spectroscopy revealed the presence of anthryl signals in the polymer underlining the successful formation of the reactive double bonds. From this first encouraging proof of a mechanochemically triggered cycloreversion of a $[2+2]$ cycloadduct, further and more detailed studies followed.

Although the first well-documented experiments were reported in 2010, earlier works had already referred to this mechanically induced cycloelimination. However, this was not investigated in detail, since there the focus was placed on crack formation events in solid state materials. ${ }^{27-30}$ The first study by Kim and co-workers in 2004 focused on light-triggered healing of the material after crack formation induced by grinding in the solid state. ${ }^{27}$ Cinnamoyl moieties were used to construct cyclobutane-based mechanophores that in the cleaved state would show high and bathocromically shifted absorptivity to undergo light-induced $[2+2]$ cycloaddition (Scheme 3). The cycloelimination was not further investigated as only a small fraction of the cyclobutanes underwent this reaction and the focus was to develop an efficient method for crack healing.

The reversibility of the mechanochemical scission of cyclobutanes was also demonstrated by heat. For this purpose, Craig and co-workers exploited the well-known heat-induced $[2+2]$ cycloaddition of trifluorovinyl ethers (TFVE) yielding perfluorocyclobutanes (PFCB) (Scheme 4). ${ }^{30}$ Employed as mechanophores in polymers, these could be healed thermally

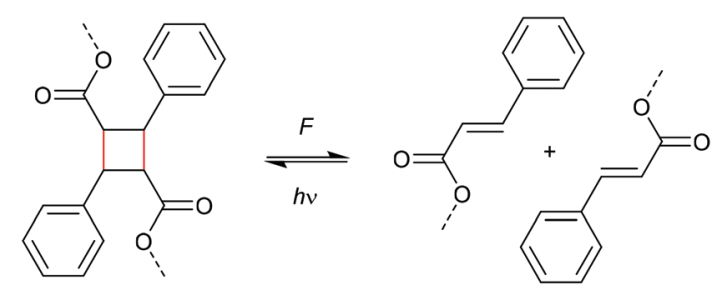

Scheme 3 Cyclobutane as crosslinker in a polymer network designed to heal upon light irradiation after grinding-induced cycloelimination. ${ }^{27}$

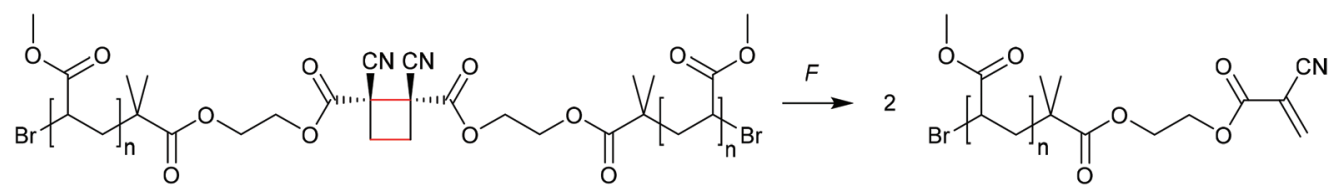

Scheme 2 Dicyano-substituted cyclobutane undergoing force-induced cycloelimination. ${ }^{24}$ 


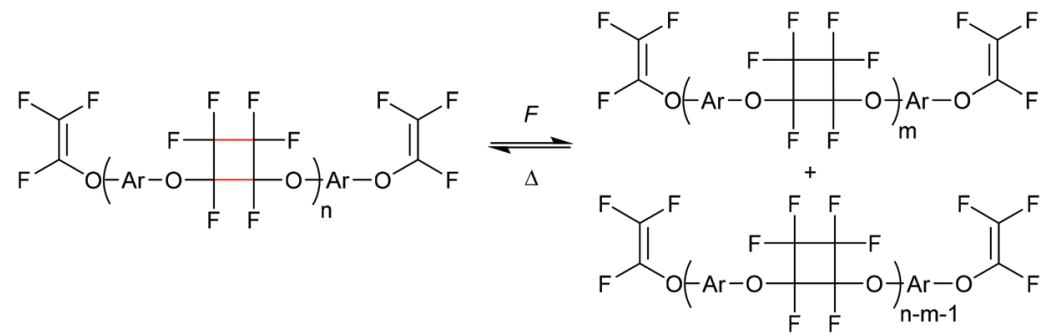

Scheme 4 Structure of the PFCB mechanophores capable of thermal healing after mechanical damage. ${ }^{30}$

after mechanochemical scission. Notably, a detailed analysis of the PFCB cycloreversion mechanism was performed, which was proposed to involve a 1,4-diradical intermediate. This interpretation was based on two observations: (i) after the sonication a fraction of PFCB showed different stereochemistry compared to the isomer of the starting cyclobutane scaffold implying that a concerted mechanism could be excluded and (ii) a radical trap added during mechanophore activation was incorporated into the polymer backbone indicating the presence of radicals.

\section{Mechanistic considerations}

The first prerogative for validating a mechanophore, concerning the exclusion of factors different from the mechanical force, was proven in detail by Craig and co-workers. ${ }^{26}$ It was verified that when mechanical force was applied to cyclobutane-based mechanophores within a polymer chain, significant dependencies on the average molar mass of the polymer chain, the dispersity in molar mass and the distribution of the mechanophore along the polymer chain arise. The latter is especially prominent in the purpose of rationalizing the force contribution and it was found that the scission rate dramatically decreased when the mechanophore was not chain-centered. On the other hand, the same activation was completely successful without any 'chain-centered' requirement when mechanical force was replaced by light as energy source.

To discuss mechanism and stereochemistry of the mechanically-induced cycloelimination of $[2+2]$ cycloadducts, a brief recapitulation of the $\mathrm{WH}$ rules is essential. ${ }^{15}$ For the $[2+2]$ cycloaddition, the number of $\pi$-electrons involved is $m+n=$ $4 q$, so necessarily $q=1$. According to the selection rules this reaction is then thermally allowed in the 'top-bottom' ( $t-b)$ and 'bottom-bottom' (b-b) addition case, i.e. for two reactants with different configuration $(Z-E$ or $E-Z)$, and is photochemically allowed only in the $\mathrm{t}-\mathrm{b}$ addition case, i.e. for two reactants with equal configuration $(Z-Z$ or $E-E)$. The stereochemistry of the addition process is reflected in the configuration of the cyclic product and due to the principle of microscopic reversibility the cycloreversion follows the same mechanisms and rules. Scheme 5 shows that the requirement for an allowed cycloreversion reaction is that the two reacting $\sigma$ bonds must have identical configurations (syn-syn or anti-anti).

Although it was strongly suggested that the mechanochemically-induced cycloreversion involved a diradical intermedi- ate ${ }^{30-32}$ the mechanism of this process was firstly investigated in more detail in subsequent works. ${ }^{15-19}$ For this, Craig and co-workers studied the mechanochemical cycloelimination of bicyclo[4.2.0]octane stereoisomers. ${ }^{33}$ The high symmetry and non-scissile nature of this mechanophore facilitated the comparison of actual and hypothetical products of the cycloelimination reaction. Scheme $6 \mathrm{a}$ and $\mathrm{b}$ show the mechanophore in syn-syn and anti-syn configuration on the scissile bonds, respectively. While the former syn-syn cycloelimination is photochemically allowed yielding the product with $E-E$ double bonds and thermally allowed yielding the $Z-E$ product, the cycloelimination from the anti-syn reactant is completely symmetry forbidden. However, the experimentally obtained mechanochemical products differ significantly from this prediction and a product mixture of $Z-Z, E-E$ and $Z-E$ was obtained starting from either syn-syn or anti-syn mechanophores (Scheme 6c). In addition, a fraction of $70-80 \%$ of the thermodynamically more stable $Z-E$ product was received in all cases. These results strongly underline a diradical intermediate obtained by homolytic bond scission as in this form bond rotation into the thermodynamically more stable proconfiguration can occur. Importantly, this means that through polymer mechanochemistry the non-WH products can be obtained as the reaction pathway can be altered significantly.

Beyond the mechanistic elucidation, the discovery of a mechanophore class is often accompanied by comprehensive evaluation of the regio- and stereochemical effects on the mechanochemical activity. Structure-activity relationships were investigated by Moore and co-workers starting from the dicyano-substituted cyclobutane structure progressively modifying its scaffold. ${ }^{34}$ They showed that the number and configuration of the substituents modulated the mechanochemical scission rate, which was confirmed by computational studies. Six different structures were assessed with either no, one, or two cyano-substituents either in $E$ - or $Z$-configuration (Scheme 7). The mechanochemical scission rate was shown to increase from $E$ - to $Z$-isomer and with increasing number of cyano substituents.

The mechanochemical scission rate in dependence of the mechanophore regioisomerism was moreover investigated by Sijbesma, Doltsinis, Hawker, Leibfarth, and co-workers. ${ }^{35}$ In this study, four-membered ketene dimers bearing polymer chain substituents in 2,4-position of the cycle (unlike the common 1,2-substitution discussed above) both in $Z$ - and 


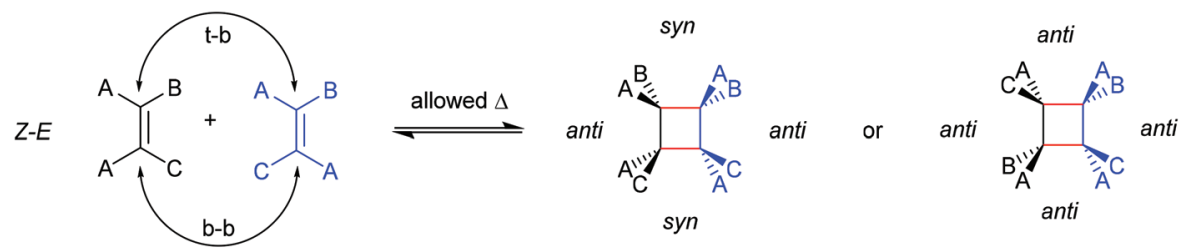

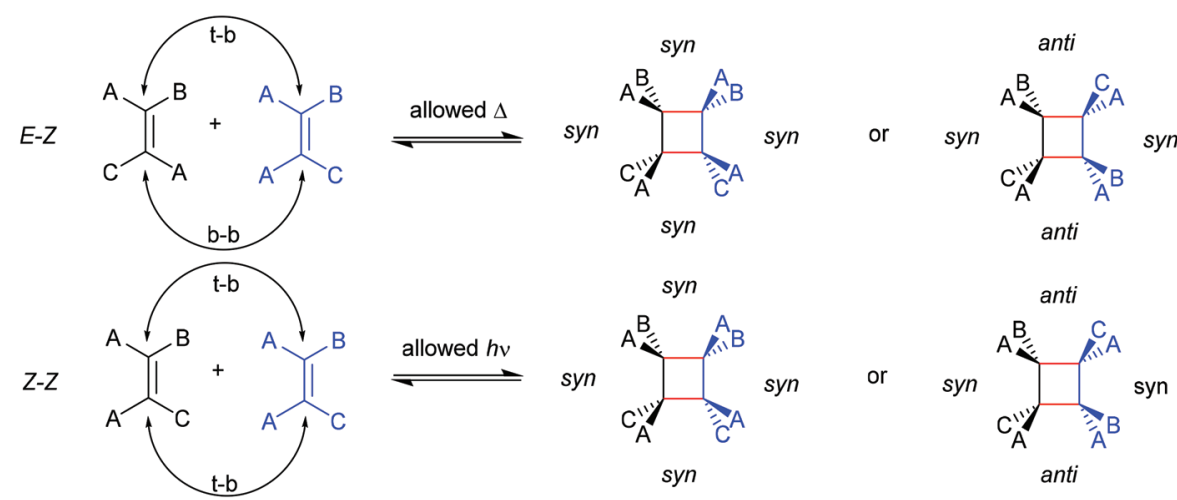

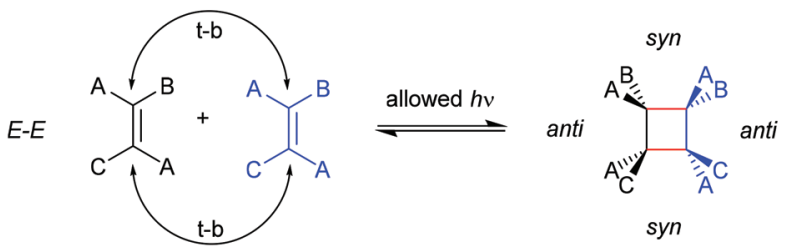

Scheme 5 Allowed pathways related to the respective configurations for both thermal and photochemical [2 + 2] cycloaddition and -elimination according to the $\mathrm{WH}$ rules.
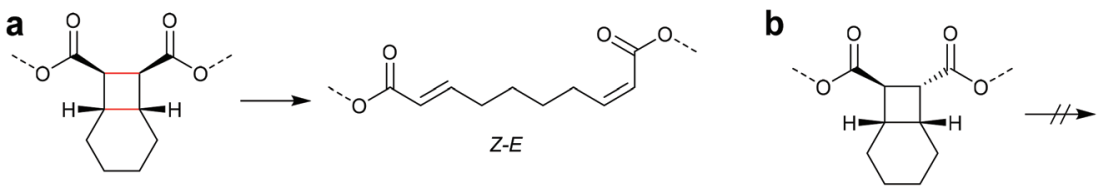

C

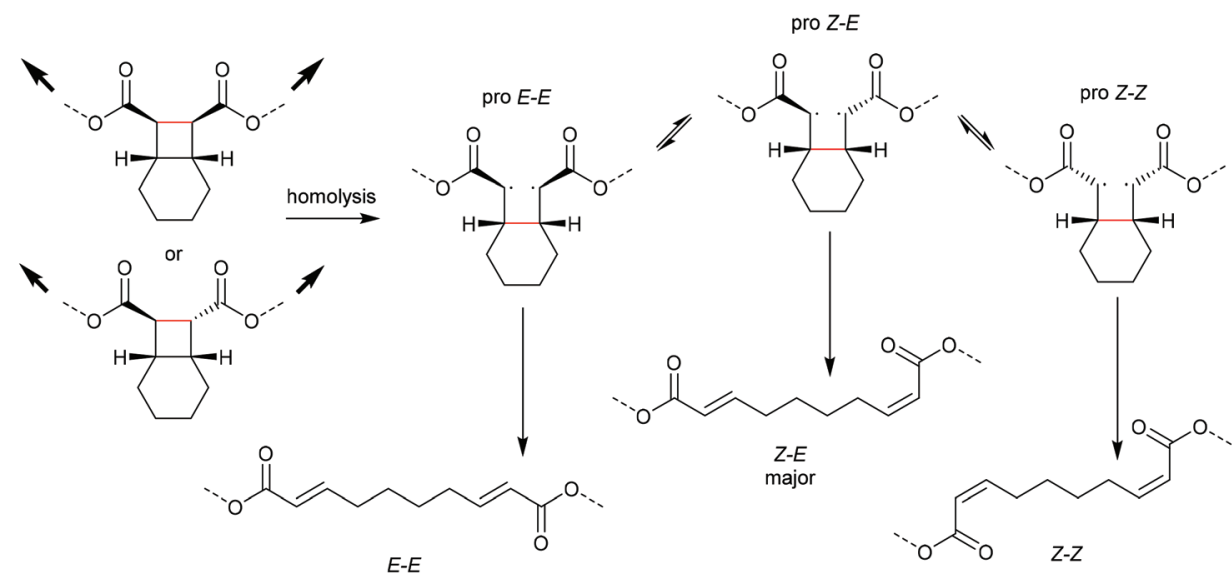

Scheme 6 (a), (b) Theoretically allowed thermal products according to the WH rules: (a) starting configuration syn-syn on the scissile bonds, the product is $Z-E$; (b) starting configuration anti-syn on the scissile bonds, the reaction is symmetry forbidden. (c) Experimentally observed mechanochemically generated products. No significant distinction between the starting configurations concerning the stereochemistry of the products can be made. This suggests formation of a diradical intermediate with three pro-conformations giving three final configurations. 

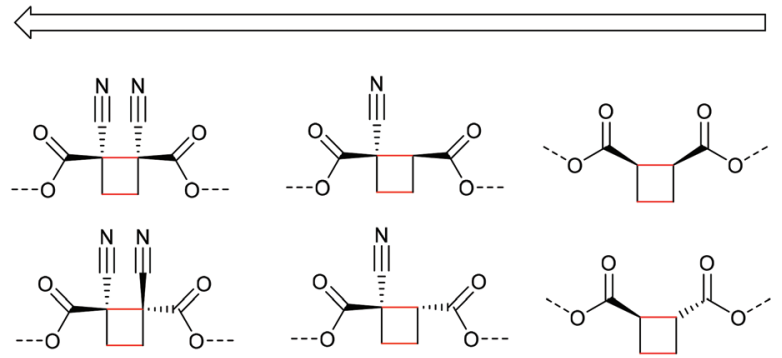

Scheme 7 Different cyclobutane derivatives studied with regard to their mechanochemical scission rate (increasing with arrow direction). ${ }^{34}$

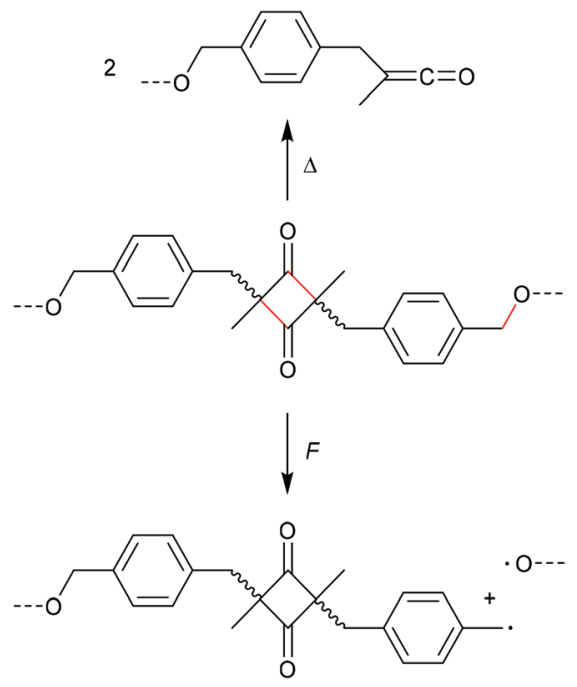

Scheme 8 Application of heat or force to a ketene dimer bearing polymer substituents in 2,4-position. ${ }^{35}$

$E$-form were evaluated (Scheme 8). While the cycloreversion towards the ketenes was observed thermally, force primarily yielded homolytic $\mathrm{C}-\mathrm{O}$ scission on the polymer attachment moieties. This observation inferred that the favoured scission route is dependent on the position of the application of the mechanical force to the molecular moiety, which was confirmed by computational simulations. The force-coupled potential energy surfaces were calculated for the cycloreversion of both $Z$ - and $E$-ketene dimer as well as for the homolytic benzylic $\mathrm{C}-\mathrm{O}$ cleavage and showed that the scission rate of the $\mathrm{C}-\mathrm{O}$ bond dramatically increased with force application. While the $E$-ketene dimer simply shows a low decrease in activation energy upon force application, the $Z$-isomer even revealed an increasing activation energy suggesting a force-induced strengthening effect.

\section{Four-membered heterocycles}

The successful mechanochemical activation of four-membered carbocycles inspired the survey of other four-membered rings that exhibit interesting functional groups upon cycloelimination. One of the most commonly occurring four-membered rings is the $\beta$-lactam scaffold and its activation by force via a<smiles>[R]C(C)(C)C</smiles><smiles>[R]N1C(=O)C(CCCC)C1C</smiles><smiles>[R7]N=CC</smiles>

b

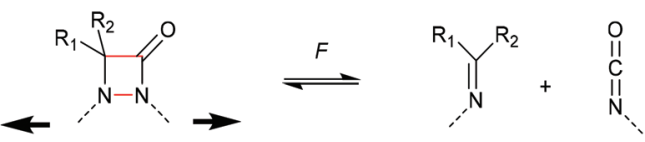

Scheme 9 Cycloelimination of (a) $\beta$-lactame-based mechanophore into ketene and imine, (b) 1,2-azetidinone-based mechanophore into isocyanate and imine.

cycloelimination was investigated by Moore and Robb (Scheme 9a). ${ }^{36,37}$ This motif dissociates into a ketene and an imine, i.e. the two reactants used for the synthesis of the $\beta$-lactam. Initially, the propensity of the $\beta$-lactam to undergo mechanochemical cycloelimination was evaluated by computational simulations. The encouraging results thereof were translated to synthesis and subsequently this motif was proven mechanochemically active, most likely via a diradical intermediate. Following a comparable approach, the mechanical cycloelimination of a 1,2-azetidinone was investigated by Craig and coworkers (Scheme 9b). ${ }^{38}$ Analogously to the $\beta$-lactam, this moiety cleaves into imine and isocyanate, the latter of which is much more useful in downstream synthetic applications due to its longer lifetime compared to ketenes. Importantly, these results demonstrate that the mechanochemical cycloelimination of four-membered rings is not limited to carbocycles alone, granting access to interesting chemical functionalities.

Another intriguing $[2+2]$ cycloadduct undergoing mechanochemically induced cycloelimination containing heteroatoms is the 1,2-dioxetane. This moiety is particularly interesting as it produces mechanoluminescence and was firstly described by Sijbesma and co-workers (Scheme 10). ${ }^{39}$ Although no mechanistic evidence was reported yet, the cycloreversion most likely occurs via a diradical intermediate. Prominently, one of the two carbonyl end groups produced after scission remains in the excited state and relaxes by emission of light. This motif was then successfully integrated into a variety of materials for optical stress sensing applications. ${ }^{40-51}$

\section{Applications}

Healing and reporting. The mechanically-induced cycloelimination of $[2+2]$ cycloadducts found various chemical and

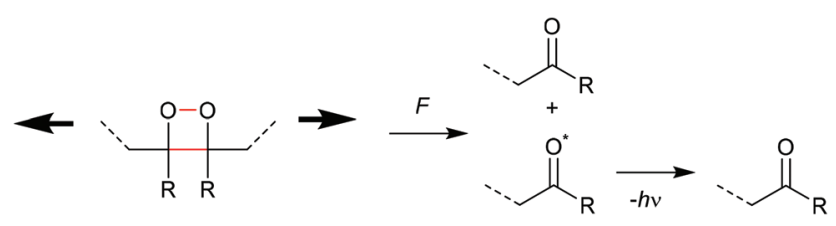

Scheme 10 Cycloelimination of a 1,2-dioxetane to the corresponding ketones of which one is in the excited state giving rise to mechanoluminescence. 

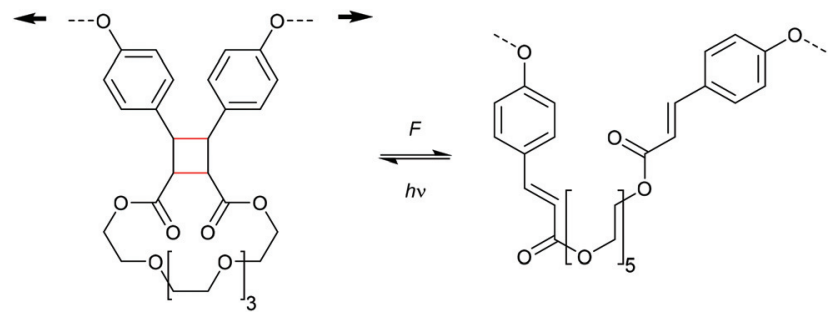

Scheme 11 Reversible fluorogenic bicyclic mechanophore based on a cinnamate dimer. ${ }^{53}$

materials science applications. ${ }^{1,52-59}$ For example, a cinnamate dimer was successfully embedded in a thermoset polymer and restored its $\pi$-conjugation upon cycloreversion hence giving rise to a fluorescence-based damage reporting nanocomposite network. ${ }^{52}$ A similar approach was developed to design a nonscissile mechanophore exhibiting mechanochromism. For this, a bicyclic structure was devised also increasing the rate of the forward $[2+2]$ cycloaddition, and thus healing after crack formation, considerably due to the increased local concentrations of the reactants (Scheme 11). ${ }^{53,54}$

Mechanochemical gating. The cycloelimination of cyclobutane was also exploited to achieve a mechanical gating effect in a non-scissile double mechanophore scaffold. ${ }^{55}$ There, the cyclobutane acted as the first mechanophore, which prevented the transmission of the mechanical force to the second mechanophore, a gem-dichlorocyclopropane ( $g \mathrm{DCC}$, vide infra). The second mechanophore was only subjected to force after the cyclobutane had already undergone cycloelimination and thus this system dissipated stress via sacrificial bonds efficiently (Scheme 12). ${ }^{60}$ Prominently, this gating technology has recently been employed to gate the degradability of polymers. ${ }^{61}$

ח-conjugated polymers. The principle of non-scissile mechanophores opens the door to exciting applications.
Notably, cyclobutane-based mechanophores were condensed in series to a ladderene structure giving rise to the concept of mechanochemical unzipping. ${ }^{1,56-59}$ Consecutive ring-opening events induced a consistent elongation of the mechanophore scaffold without scission of the main chain concurrently generating a series of conjugated double bonds (Scheme 13). As the resulting polymer bore features of polyacetylene, this process was exploited to switch the electronic proprieties of the resulting material from insulating to semiconducting. Most notably, Martinez, Xia and co-workers recently showed that this unzipping mechanism always involves either all or no mechanochemical activations of cyclobutane mechanophores within the structure. ${ }^{59}$

\section{Cycloelimination of [4 +2] cycloadducts (retro-Diels-Alder reaction)}

\section{Scissile activation of $[4+2]$ cycloadducts}

The formal $[4+2]$ cycloelimination or retro-Diels-Alder (rDA) reaction is commonly known as a thermo-reversible reaction in which a $[4+2]$ cycloadduct reacts to the corresponding diene and dienophile. ${ }^{62}$ For polymer mechanochemistry, the rDA was first observed in healable materials. ${ }^{63}$ As the rDA occurred during crack formation in polymer networks crosslinked with a DA motif, these could be mended at elevated temperatures by the forward DA cycloaddition. ${ }^{64}$ Two DA motifs studied by Yoshie and co-workers were established in this context: the furan-maleimide $(\mathrm{F}-\mathrm{M})$ and the anthracene-maleimide (A-M) cycloadduct (Scheme 14). ${ }^{65,66}$

Though it was shown that these healable motifs underwent mechanochemically induced bond scission, their thorough investigation as mechanophores was realized only in sub-

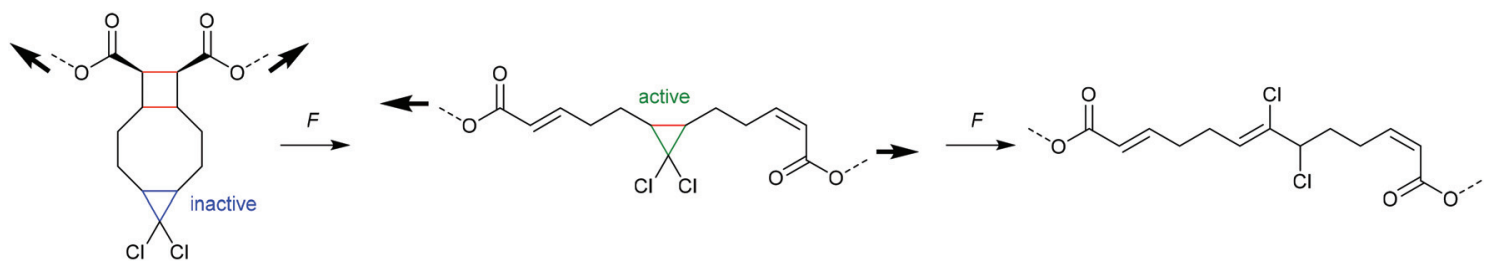

Scheme 12 Copolymer of cyclobutane- and gDCC-based mechanophores to achieve a mechanical gating effect. ${ }^{55}$

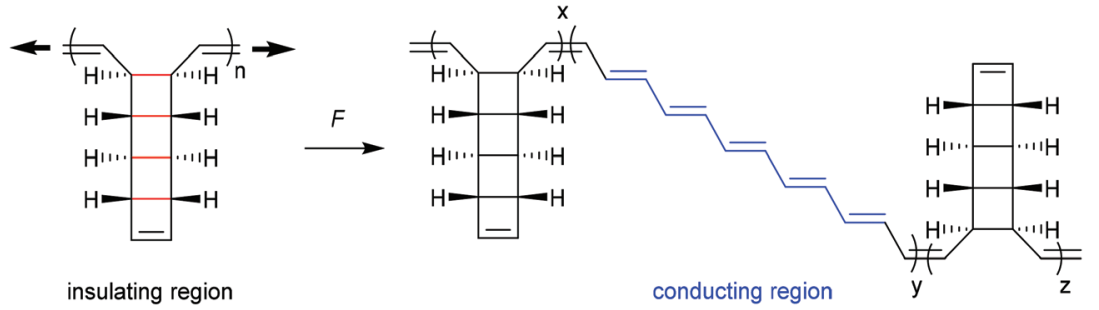

Scheme 13 Mechanical unzipping of polyladderenes. 
a

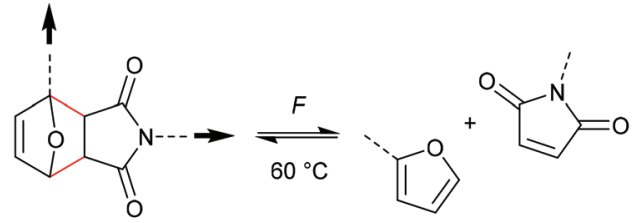

b 1<smiles>CN1C(=O)C2C3c4ccccc4C(I)(c4ccccc43)C2C1=O</smiles><smiles>CN1C(=O)C=CC1=O</smiles>

Scheme 14 (a) Furan-maleimide and (b) anthracene-maleimide DA adducts and their respective thermoreversible activation by force.

sequent, later works. Up to today, $\mathrm{F}-\mathrm{M}$ and $\mathrm{A}-\mathrm{M}$ mechanophores were used in various materials with different properties, including linear and star-shaped polymers, ${ }^{67-70}$ at heterointerfaces, ${ }^{71-73}$ hydrophilic and hydrophobic diblock copolymer micelles, ${ }^{74,75}$ hydrogels, ${ }^{76}$ and in combination with slide-ring materials. ${ }^{77}$ The $\mathrm{F}-\mathrm{M}$ and A-M rDA mechanophore activation was investigated with standard procedures, such as compression of bulk solid state materials ${ }^{78}$ and ultrasonication of solutions ${ }^{79}$ but also by solvent swelling, ${ }^{80}$ laserinduced stress waves, ${ }^{81}$ and recently also single-molecule force spectroscopy (SMFS). ${ }^{73}$

Makarov, Bielawski and co-workers carried out the first systematic investigations on the $\mathrm{F}-\mathrm{M}$ and $\mathrm{A}-\mathrm{M}$ cycloadducts as mechanophores in a trendsetting work. ${ }^{82}$ They used both computational simulations and synthetic experiments to investigate the effect of the substitution pattern of the attached polymer chains. For the F-M cycloadduct, computation suggested that force application in proximal position (Fig. 1a; blue) would mechanochemically accelerate the cycloelimina- tion reaction whereas force application in distal position (Fig. 1a; red) would decelerate mechanochemical reactivity. For the A-M cycloadduct, calculations and experimental data proposed that a substitution in 2-position would completely suppress the mechanochemical cycloelimination (Fig. 1b; red). Confirming this result, no mechanochemical activation was monitored experimentally, whereas the commonly used 9-position remained accessible for the force-induced rDA (Fig. 1b; blue).

Stevenson and De Bo systematically expanded these results for the F-M cycloadducts and additionally differentiated between the endo- and exo-stereoisomers. ${ }^{83}$ These were investigated with distal and proximal substitution patterns regarding the attachment points of the polymer chains and incorporated within the central region of linear PMA (Fig. 2). Whereas expectedly the endo-stereoisomers thermally cleaved at a

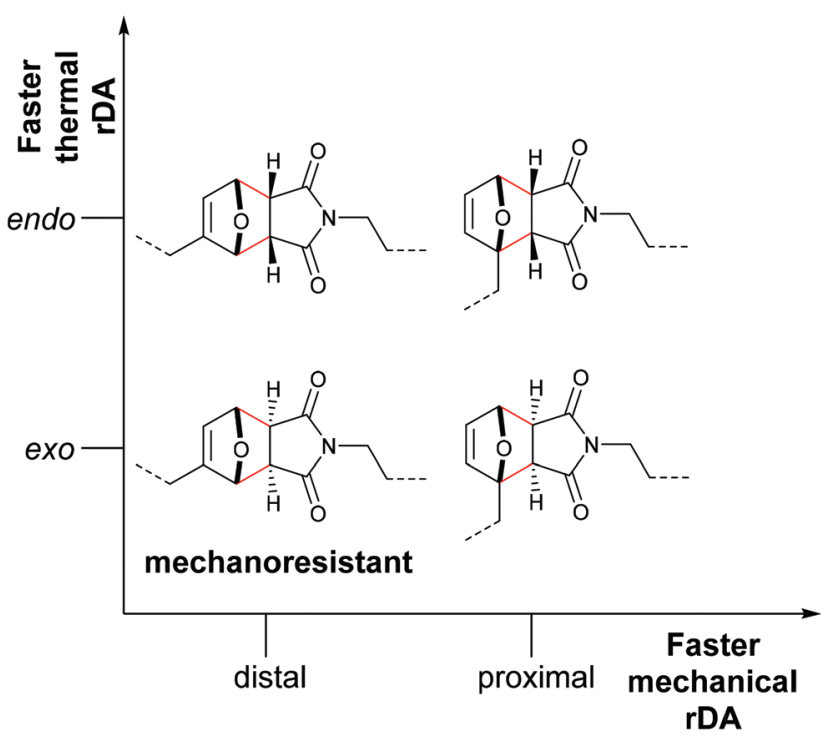

Fig. 2 Influence of the regio- and stereochemistry in the thermal and mechanochemical cycloelimination of F-M cycloadducts. ${ }^{83}$
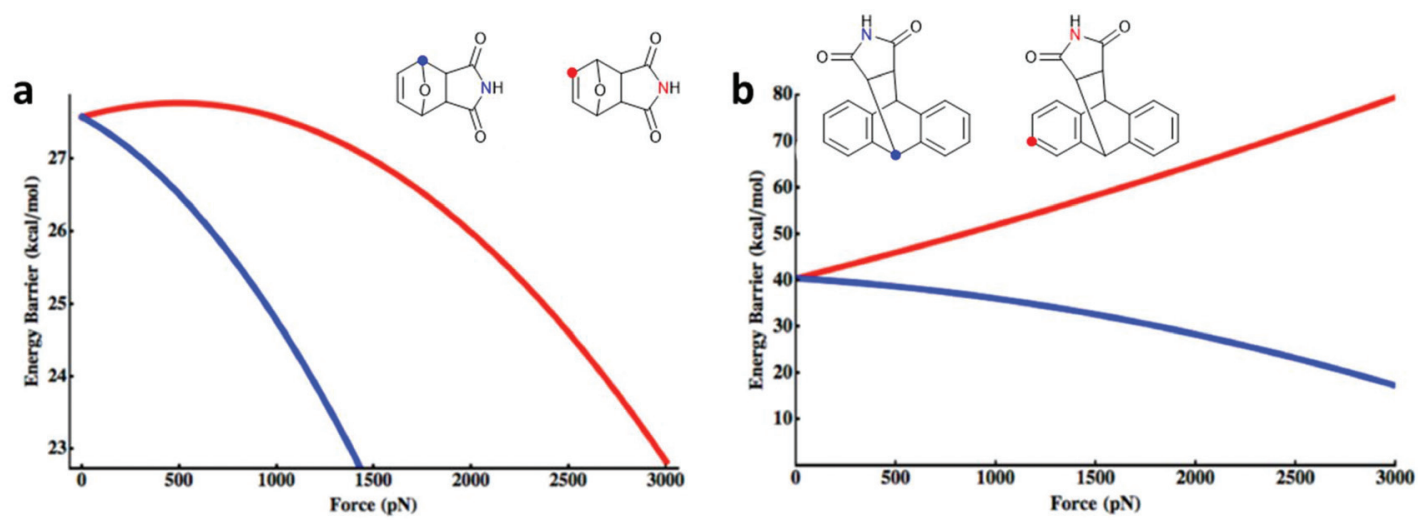

Fig. 1 Force-dependent activation energy for the cycloelimination depending on the substitution pattern in DA cycloadducts of (a) $F-M$ and (b) A-M. Adapted with permission from ref. 82. Copyright 2013 American Chemical Society. 
higher rate than the exo-variants, the mechanochemical rate was found to depend more on the attachment points of the polymer chains than on the stereochemical identity of the DA adducts. In agreement with the investigations by Makarov and Bielawski discussed above, the proximal isomers reacted at a higher rate than the distal isomers. Importantly, the distal exocycloadduct could not be cleaved by force and appeared to be mechanochemically inactive. This was further underlined by computational simulations, in which the distal exo-adduct led to non-selective bond scission.

Notably, Wang and Craig saw room for improvement with regard to the method employed by Stevenson and De Bo to differentiate between endo- and exo-adduct mechanochemical activity. ${ }^{84}$ By combination of the scissile F-M DA adducts with the non-scissile gDCC (vide infra) motifs, they found that the endo-stereoisomers were mechanochemically more labile than their exo-counterparts.

Otsuka and co-workers combined the F-M DA mechanophore with a photochromic diarylethene (DAE) unit providing a photoregulated lock for mechanochemistry (Scheme 15). ${ }^{85}$ In the ring-open form DAE the adduct could be cleaved selective through the rDA reaction, but after isomerization to the ringclosed form via UV-irradiation the mechanophore was inert toward elongational forces due to the removal of the crucial double bond from the DA adduct. ${ }^{86-88}$ In their study they also synthesized and sonicated a control mechanophore with distal geometry without observing any activation. They calculated the required energy and force $\left(E_{\max }=770 \mathrm{~kJ} \mathrm{~mol}^{-1}\right.$ and $F_{\max }=5.19$ $\mathrm{nN}$ ) and confirmed the previously discussed reports regarding the stability of distal isomers. ${ }^{82-84}$ Notably, Robb and coworkers reported the inverse case, i.e. a mechanoregulated lock for photochemistry, with a cyclopentadiene-bridged DAE in a DA adduct with maleimide. ${ }^{89}$

During their efforts to tailor the optical properties of anthracenes released during cycloelimination of A-M DA cycloadducts, Göstl and co-workers also synthesized the untypical 1,4-cycloadduct of a 9,10- $\pi$-extended anthracene
(Scheme 16). ${ }^{90,91}$ Importantly, while polymer substituents coupled the force to the 9- and 10-positions, they were not directly attached to the quaternary carbon atoms participating in the cycloelimination reaction in 1,4-position. This led to the absence of mechanochemical reactivity via the rDA pathway for this derivative highlighting once more the findings of Makarov and Bielawski discussed above. It is likely that the force vector did not align well with the reaction coordinates, yet high thermodynamic stability of the 1,4-cycloadduct could not be excluded since no further investigations on these derivatives were performed. ${ }^{90}$

\section{Mechanistic considerations}

For successful prediction of activation free energies for reactions under force it is necessary to revisit the reaction mechanism. DFT calculations by Makarov, Bielawski and co-workers suggested that the rDA in the absence of force proceeded in a

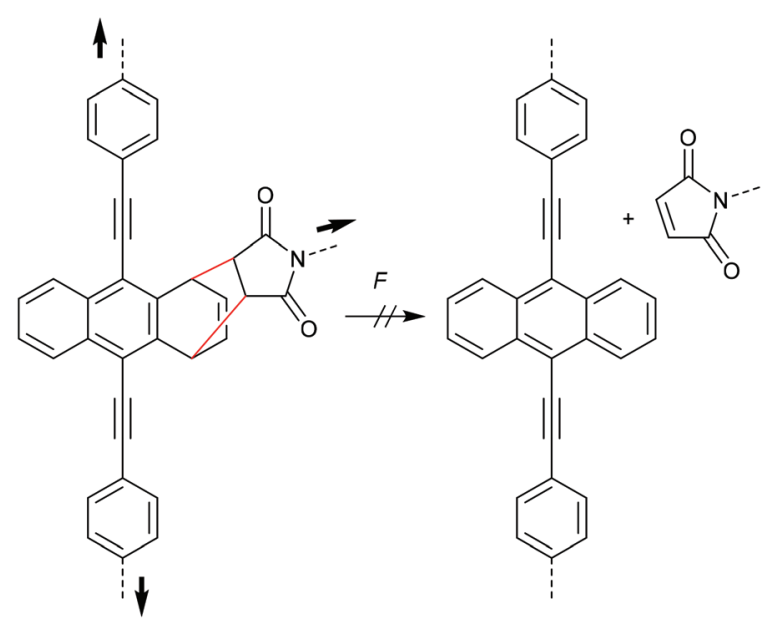

Scheme 16 1,4-cycloadduct of 9,10- $\pi$-extended anthracene and maleimide resistant to force-induced cycloelimination. ${ }^{90}$
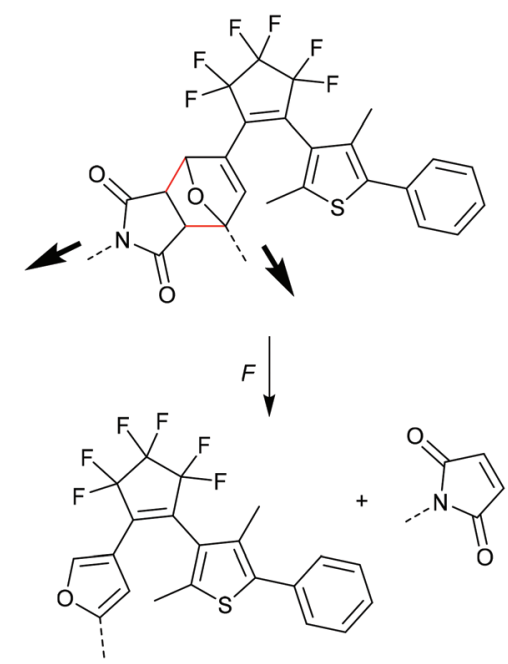

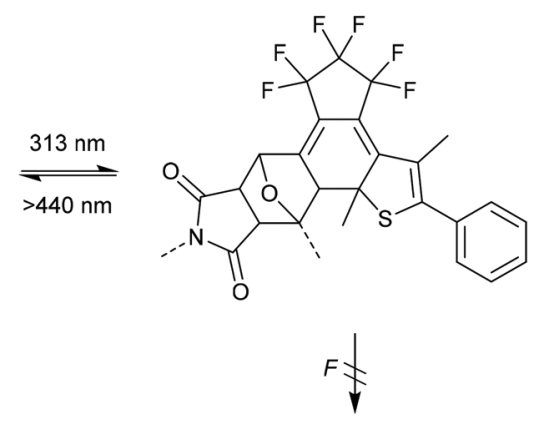

Scheme 15 DAE DA mechanophore with a photoregulated lock for mechanochemistry. ${ }^{85}$ 
concerted mechanism (Fig. 3a, top). ${ }^{82}$ Akbulatov and Boulatov compared those computational simulations with other DFT functions (e.g. uMPW1K) and also predicted the existence of an alternative two-step radical dissociation pathway (Fig. 3a, bottom). ${ }^{19}$ Although the required energy for this path was, compared to the concerted mechanism, considerably higher in

a
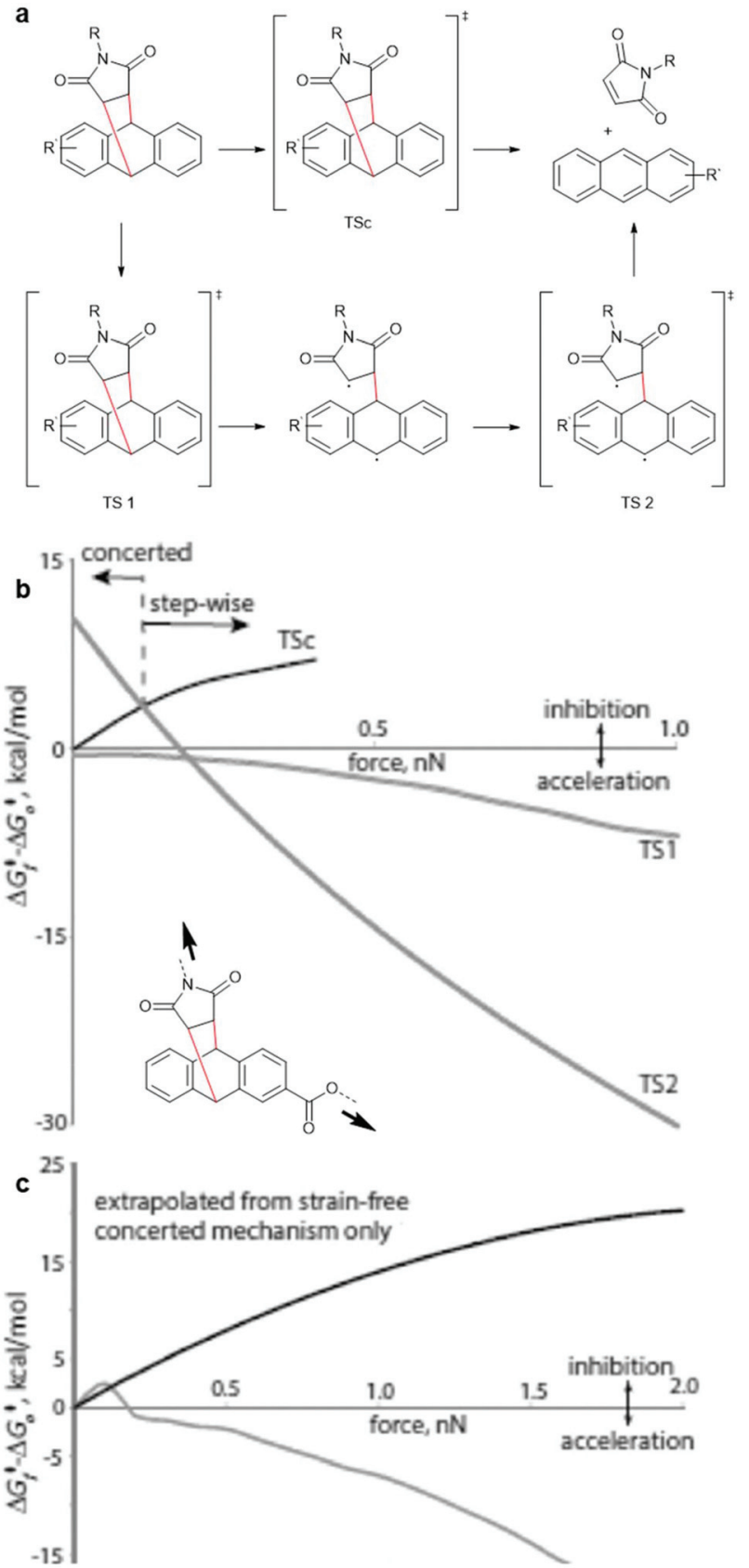

Fig. 3 (a) Concerted (top) and stepwise radical (bottom) mechanism for the dissociation of DA adducts under force. (b) Changes in the free energies of the transition states relative to the reactants as a function of applied force (uMPW1K/6-31+G(d)). (c) A comparison of dissociation barrier calculated by Akbulatov and Boulatov (grey line) with the predicted one by Makarov and co-workers. Adapted from ref. 19 with permission from Wiley-VCH Verlag GmbH \& Co. KGaA, copyright 2017. a reaction without force, small forces were shown to invert this order (Fig. 3b and c). The stepwise radical mechanism was already dominant at an applied force of $c a .0 .1 \mathrm{nN}$. The concerted mechanism, on the other hand, was disfavoured under force and was abandoned completely at forces of $c a$. 0.4-0.8 $\mathrm{nN}$, depending on the DFT function used and the substituents attached to the motif. Therefore, dissociation of DA adducts was inhibited at small forces $(0.1 \mathrm{nN})$ but accelerated with increasing force.

\section{Flex activation of $[4+2]$ cycloadducts}

A distinctively alternative way to mechanochemically induce the cycloreversion of $[4+2]$ cycloadducts was developed with the so-called 'flex activation'. In contrast to the activation via the scission of internal bonds that are elongated with the force vector of the attached polymer segments, for flex activation the polymer scaffold is used to distort bond angles releasing small molecules. ${ }^{92}$ Boydston and co-workers pioneered this method for the release of furan derivatives (Scheme 17). ${ }^{92-94}$ They converted main chain alkene moieties in oxanorbornadiene DA adducts constructed from furan and dimethyl acetylenedicarboxylate (DMAD) into alkynes in a cycloelimination reaction. Incorporation of the DA adducts as crosslinker into PMA or polyurethane networks followed by compression proved the release of small furan-containing molecules. Calculated potential energies estimate an activation energy of $c a .35 \mathrm{kcal} \mathrm{mol}^{-1}$ for this process.

Roessler and Zimmerman used the growing string method (GSM) without using the $\theta$ value as a constraint coordinate and showed that the reaction mechanism for the flex activation depended on the applied force. ${ }^{95}$ The activation energy decreased mostly linearly with increasing force and was approximately $24 \mathrm{kcal} \mathrm{mol}^{-1}$ if $4 \mathrm{nN}$ of force were applied relative to the ground state reaction. Transition states calculated with different applied forces showed unique $\theta$ values, indicating that the reaction followed a multiparameter pathway and force influenced only one reaction coordinate.

The concept of flex activation was moreover exploited for anthracene DA adducts (Scheme 18). The attachment of polymer chains in 2,6-position of a cycloadduct of anthracene and phenyltriazolinedione, however, only showed 1\% mechanochemical cycloelimination in a strained PDMS network at $125{ }^{\circ} \mathrm{C}$ (Scheme 18a). ${ }^{96,97}$ These harsh conditions are not surprising, as triazolinediones are among the most reactive
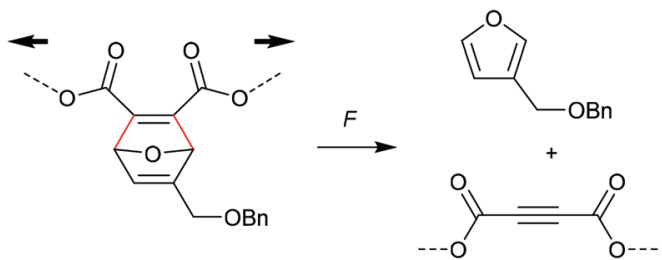

Scheme 17 Flex activation via transient bond angle distortion of oxanorbornadiene DA adducts and subsequent cycloelimination without internal polymer bond scission. 
a<smiles>C=Cc1ccc2c(c1)C1c3ccc(C=C)cc3C2n2c(=O)n(-c3ccccc3)c(=O)n21</smiles><smiles>Cc1ccc2cc3ccc(C)cc3cc2c1</smiles><smiles>O=C1N=NC(=O)N1c1ccccc1</smiles>

b
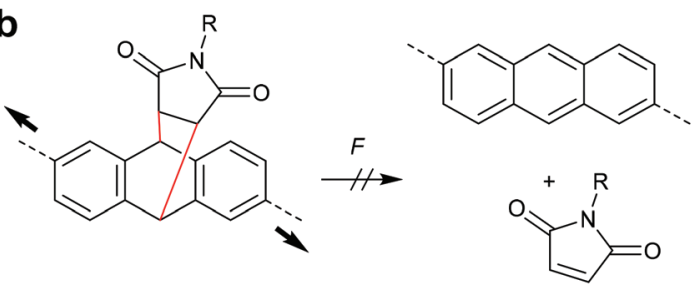

Scheme 18 Flex activation of anthracene cycloadducts with (a) phenyltriazolinedione and (b) maleimide. ${ }^{78,96,97}$

known dienophiles forming cycloadducts with extreme thermodynamic stability. In contrast, no flex activation was observed for a comparable anthracene maleimide cycloadduct (Scheme 18b). ${ }^{78}$

\section{Cycloelimination of [3+2] cycloadducts}

\section{The debate over 1,2,3-triazoles as mechanophores}

One of the most energetically debated motifs regarding its mechanochemical activity is the 1,2,3-triazole undergoing force-induced cycloelimination. The forward reaction is the 1,3-dipolar Huisgen cycloaddition and is counted to the variety of 'click' reactions. The scepticism towards this cycloelimination was fuelled by the retraction of the prominent first investigation of a 1,2,3-triazole carrying polymer substituents in 1,4-position claiming to be 'unclicking the click' by Bielawski and co-workers (Scheme 19). ${ }^{98,99}$

In a later study, Bielawski, Makarov and co-workers set out to examine the reliability of their retracted results and firstly discussed the regiochemical effects of this cycloelimination

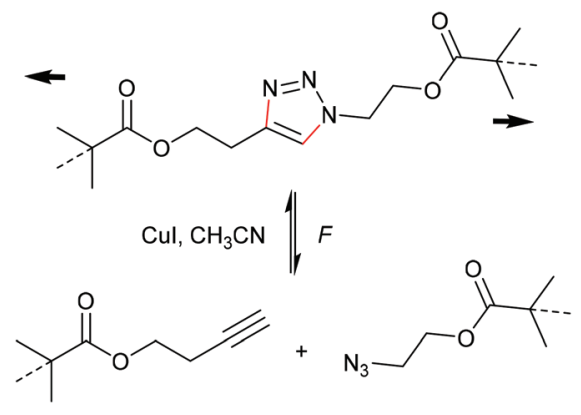

Scheme 19 Supposed force-induced cycloelimination of the triazole mechanophore yielding azide and alkyne moities. ${ }^{98,99}$

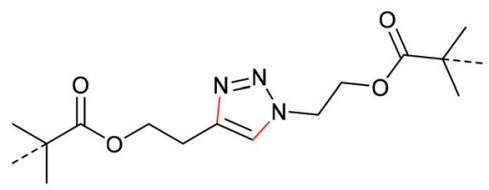

1,4-disubstituted triazole

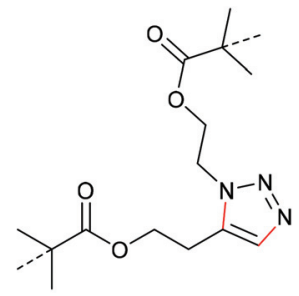

1,5-disubstituted triazole
Scheme 20 Structures of 1,4- and 1,5-disubstituted triazole mechanophores.

reaction by comparing the mechanochemical scission rate of 1,4-substituted with 1,5-substituted triazoles (Scheme 20). ${ }^{100}$ There, they found a slightly increased scission rate for the 1,5substituted triazole derivatives which is a very notable finding hinting towards two distinct scission mechanisms, though the rate difference of $c a .20 \%$ was rather small.

Trying to shine light on this debate, Uggerud and Smalø performed computational simulations in order to mechanistically explain the mechanochemically facilitated cycloreversion of the 1,4-substituted triazoles. ${ }^{101}$ They found that unspecific chain dissociation, i.e. rupture of the macromolecular backbone, was favoured over the cycloreversion reaction, though the latter was still deemed possible from a theoretical mechanochemical point of view. Hartke, Lüning, Beyer and co-workers even went as far to design and synthesize a 1,4-disubstituted triazole and bridge it with a second cycle turning this previously scissile mechanophore into a non-scissile motif that can be analysed by SMFS employing an atomic force microscope (AFM) (Scheme 21). ${ }^{102}$ Upon stretching the covalently anchored molecule (between two PEG chains, attached to $\mathrm{Si}_{3} \mathrm{~N}_{4}$ ) a characteristic length increase was to be measured in the case of rupture along the triazole branch. While the authors clearly observed and measured a threshold cleaving force on this motif of 1-2 $\mathrm{nN}$, it remained unclear whether these events were indeed attributable to cycloelimination reactions or unspecific chain scission.

Another work raising doubts regarding the mechanochemical activity of the 1,4-disubstituted triazoles was published by Xia and co-workers who prepared amphiphilic block copolymer micelles connecting the blocks with the triazole motif. ${ }^{103}$ Upon irradiation with high-intensity focused ultrasound (HIFU), they also found that chain scission preferentially occured on the incorporated ester bonds within their polymers and not on the triazole moiety. However, the effects of HIFU on mechanophores are only scarcely investigated and hence comparability of these measurements is limited. Yet, Dreuw and Stauch principally confirmed these results by computational simulation. ${ }^{104}$ They deemed the cycloreversion of 1,4substituted triazoles impossible if forces are conducted to aliphatic linkers since the entire mechanochemically robust triazole ring would need to be activated and a rupture event in the aliphatic chain would be energetically much more favour- 


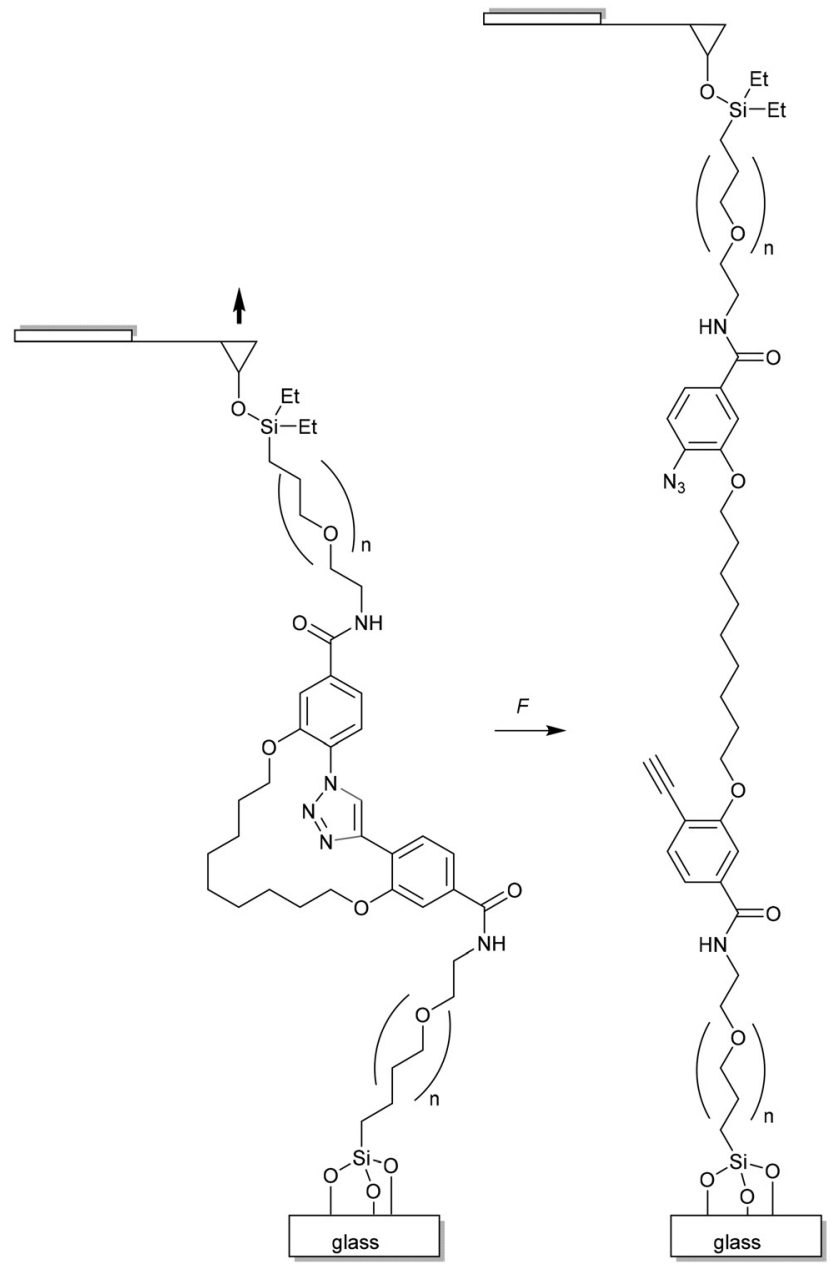

Scheme 21 Supposed mechanochemical cycloelimination of the nonscissile bridged 1,4-disubstituteted triazole mechanophore in AFM measurements. ${ }^{102}$

able. However, cycloelimination of 1,5-substituted-triazoles should be possible because of the alignment of the scissile bond with the force vector, although a competition with the rupture of the $\mathrm{C}-\mathrm{N}$ bond at the pulling point should be observed in stretching experiments due to similar force and energy rupture requirements of these bonds.

Eventually, Marx and co-workers dismissed, also on a computational level, the mechanochemically induced cycloreversion of 1,4-substituted triazoles by $\mathrm{Cu}^{\mathrm{I}}$-catalysis - analogously to the forward reaction and according to the principle of microscopic reversibility. ${ }^{105}$ Destructive pathways were favourable when the desired activation free energies were compared. In contrast, a Ru-assisted mechanochemical unclicking of the 1,5-regioisomer could lower the activation free energy for the rate-determining step drastically rendering the reaction feasible.

Blank and co-workers revived the triazoles as mechanophores undergoing cycloelimination in a new context when they investigated the cycloadducts from substituted azides with molecularly strained cyclooctyne derivatives being an important in vitro and in vivo ligation motif in the realm of the biological sciences. ${ }^{106}$ Employing computational simulations, they compared various 1,4- and 1,5-substituted triazoles and confirmed the previous experiments from Bielawski, Makarov and co-workers ${ }^{100}$ stating that 1,5 -substituted triazoles were more suitable for a force-induced cycloelimination reaction. It was found that 1,5-substituted triazoles opened via an unzipping mechanism in comparison to a shear mechanism in the case of their 1,4-substituted counterparts. Using these cyclooctyne-azide cycloadducts in single molecule force experiments using AFM, Fang, Shahbazian-Yassar and co-workers designed an on-surface reaction cascade that ligated cyclooctyne generated by the mechanochemically induced cycloelimination with gold nanoparticles (AuNPs) to confirm the local character of their experiments. ${ }^{107}$

The force-induced cycloelimination of 1,4-disubstituted triazoles on unstrained alkynes appears to be an unlikely reaction. In simulations and experiments, the required forces to cleave the triazole ring in a shear mechanism were too high and led to undesired rupture events in the adjacent polymer chains. Conversely, 1,5-substituted triazoles and triazoles with strained cyclooctyne were found to be suitable motifs.

\section{Cycloelimination of [4 + 4] cycloadducts}

\section{Anthracene dimer}

Very analogously to the mechanophores discussed above, the polymer mechanochemical cycloelimination of $[4+4]$ cycloadducts was first observed in the context of photohealable materials. For this purpose, anthracene moieties undergoing a photoreversible $[4+4]$ cycloaddition were used. ${ }^{108,109}$ Dimerization and dissociation of the anthracene and its respective cycloadduct both are accessible by irradiation with light of different wavelengths (Scheme 22). Such scaffolds and their capability of reversible dimerization were studied by Landfester and co-workers, who successfully integrated them into a dendritic, photohealable material. ${ }^{109}$

Within healable materials, induced damage is generally of mechanical nature and hence it was reasonable to assume that the corresponding cycloelimination was also accessible via the application of force. ${ }^{110-117}$ Chung and co-workers investigated

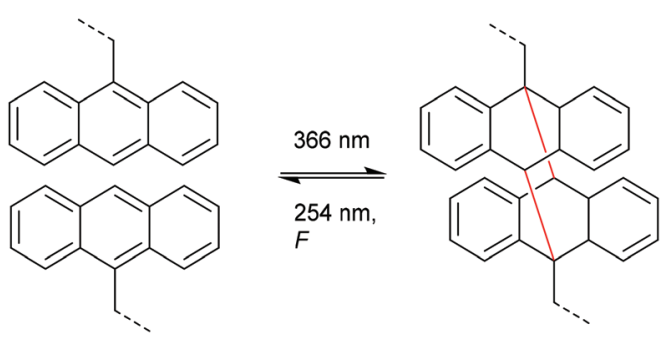

Scheme 22 Photoinduced [4 + 4] anthracene dimerization and photoas well as mechanochemical cycloelimination. 
a polymer network bearing the anthracene dimer as crosslinker. ${ }^{110}$ Upon grinding the polymer network, fluorescence emission stemming from the formation of the individual anthracene moieties was recorded thus confirming the successful cycloelimination (Scheme 22). This optical response was exploited as crack sensor with comparably high molar absorptivity and fluorescence almost in the visible region of the spectrum.

The cycloelimination of anthracene dimer induced by mechanical force applied through pressure was also studied more in detail from a kinetic and mechanistic point of view by Chronister, Bardeen and co-workers. ${ }^{111}$ Macroscopically, an increase of pressure resulted in a dramatic acceleration of the dissociation. This is counterintuitive as dissociative reactions usually exhibit positive activation volumes. These results suggested that pressure acted as catalyst rendering this a purely kinetic effect due to a less voluminous transition state. It was proposed that pressure stabilized the transition state by flattening the anthracene rings, followed by rupture and dissociation - a concept comparable to the 'flex activation' discussed above.

\section{Mechanistic considerations}

Though the cycloelimination of $[4+4]$ cycloadducts was shown to be promoted by mechanical force, no evidence about the mechanistic pathway it follows were presented yet. Computational simulations suggested that the diradical intermediate was energetically favoured compared to the concerted dissociation pathway. ${ }^{118}$ A radical mechanism would be in agreement with previous reports concerning the mechanochemical cycloelimination of $[2+2]$ and $[4+2]$ cycloadducts. However, for $[4+4]$ cycloadducts no trapping experiments or spectroscopic analyses were performed that could confirm the existence of a metastable diradical intermediate.

Yet, a fundamental theoretical study that aimed to elucidate the fairly high rate of the mechanochemical anthracene dimer cycloelimination was performed on the basis of a comparison with the cyclobutane mechanophore. ${ }^{119}$ Within the anthracene dimer two cyclooctane rings share two covalent bonds connecting the anthracene moieties. Hence, a comparative study between the cyclobutane and a virtual cyclooctane mechanophore were performed. While the cyclobutane showed a ring strain of ca. $26 \mathrm{kcal} \mathrm{mol}^{-1}$ and a BDE of ca. $72 \mathrm{kcal} \mathrm{mol}^{-1}$, cyclooctane reasonably exhibited a lower ring strain of $c a$. $10 \mathrm{kcal} \mathrm{mol}^{-1}$ and a BDE of $c a .160 \mathrm{kcal} \mathrm{mol}^{-1}$. The ring strain was established as inversely proportional to the BDE and simple cyclooctane was hence shown not to undergo any scission by mechanical force. However, within the anthracene dimer the BDE drastically decreased to $59 \mathrm{kcal} \mathrm{mol}^{-1}$ - even lower than the BDE of cyclobutane. This suggested a high ring strain within the anthracene dimer motif and was invoked to explain the high mechanical sensitivity of this motif.

\section{2-Electron electrocyclic ring-opening reactions}

\section{Gem-dihalocyclopropanes ( $g \mathrm{DHCs}$ )}

An electrocyclic reaction is a pericyclic rearrangement in which one $\pi$ bond is converted to one $\sigma$ bond or vice versa following either a ring-opening or ring-closing mechanism, respectively. The first proof of a mechanochemically induced 2-electron ring-opening reaction was presented by Craig and coworkers. ${ }^{120}$ They incorporated multiple gDCCs within a backbone of $Z$-poly(butadiene) (PB) by reacting the $\mathrm{PB}$ with $\mathrm{NaOH}$ in $\mathrm{CHCl}_{3}$ under phase-transfer conditions resulting in dichlorocarbene addition. These $g$ DCC polymers underwent mechanochemical ring-opening in conjunction with chlorine migration several hundred times within a single polymer chain, providing a 'mechanochemical map' of the stress distributions within linear polymer chains during ultrasonication in solution (Fig. 4).

The approach of modifying a $\mathrm{PB}$ backbone was consequently extended to other $g$ DHCs. ${ }^{121-128}$ Notably, Craig and coworkers found by ozonolysis of mechanochemically formed double bonds that those regions of the polymer that did and
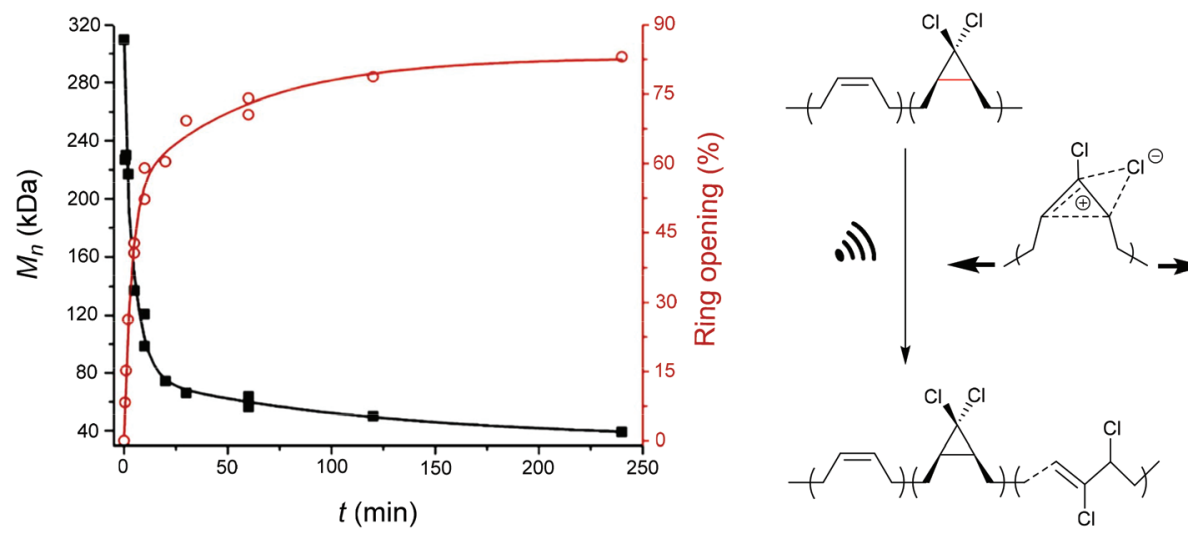

Fig. 4 Ultrasonication of $g$ DCC-PB copolymer leads to ring-opened 2,3-dichloroalkenes $(O)$ with simultaneously decreasing $M_{n}(\square)$. Adapted with permission from ref. 120. Copyright 2009 American Chemical Society. 
those that did not undergo force-induced ring-opening were continuous, indicating a smooth and monotonic force reduction from the central chain section towards the termini. ${ }^{125}$ Moreover, compressive force could be used to perform the ring-opening reaction, but tensile load resulted in no measurable activation, even when applied to the point of failure of the material. ${ }^{124}$ This was attributed to the minimum domain size for successful mechanochemical activation, which was found to be larger than a single monomer and hence heterogeneous stress distribution within the employed polymer framework needed to be taken into account. In addition, a versatile method for the abundant incorporation of cyclic mechanophores into high molar mass block copolymers with excellent long-term stability was developed. ${ }^{129,130}$ This allowed access to ABA-type block structures with the mechanophore-rich region in the chain centre allowing high mechanochemical turnover.

\section{Mechanistic considerations}

Force trapping the transition state. Further studies on the $g$ DHC mechanophores revealed that force could alter the commonly thermally observed disrotatory ring-opening mechanism into a conrotatory pathway by a diradical transition state formally violating the $\mathrm{WH}$ rules. ${ }^{131}$ First elucidating the diradical transition state, Craig and co-workers transformed the thermodynamically more stable gem-difluorocyclopropane ( $g$ DFC) $E$-isomer into the less stable $Z$-isomer (Scheme 23). ${ }^{121}$ Mechanochemical activation ring-opened the gDFCs and trapped a 1,3-diradical that can be formally seen as the transition state of the thermal variant of this electrocyclic reaction. $^{123}$ By this 'force trapping', the diradical lived long enough that its participation in bimolecular addition reactions could occur. Moreover, the application of transient tensile force induced a net isomerization of the $g \mathrm{DFC} E$-isomer into its thermodynamically less stable $Z$-isomer, leading to the counterintuitive result that the $g$ DFC-containing polymer con-

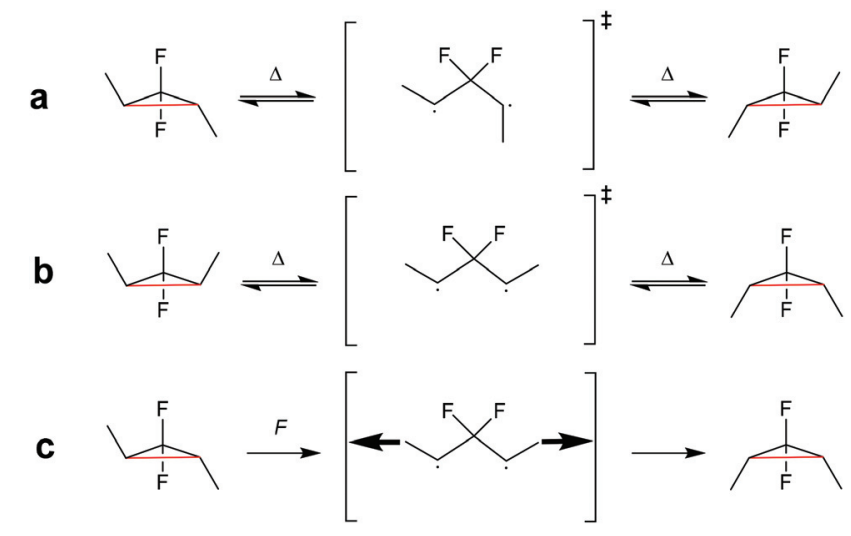

Scheme 23 (a) gDFC E-isomer and (b) Z-isomer thermally ring-open and -close through a disrotatory process via 1,3-diradical transition state. (c) Force leads to the formation and trapping of the 1,3-diradical transition state, which ring-closes to the $g D F C Z$-isomer once force is removed. ${ }^{123}$

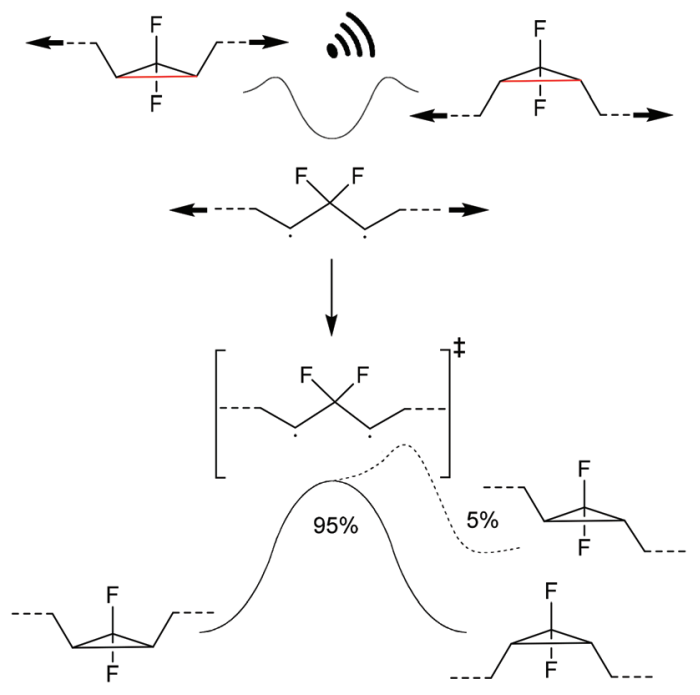

Scheme 24 Ring-closing of a force trapped diradical transition state leading i.a. to $5 \%$ anti-WH products. ${ }^{132}$

tracted in response to extensional force. These observations suggested the possibility of using force not only to bias reaction pathways, but also to directly characterize reaction potential energy surfaces typically inaccessible by experiments.

Investigating the thermally symmetry-forbidden conrotatory ring-closing after force trapping the diradical transition state, Martinez, Craig and co-workers prepared purely $Z$-form $g$ DFCsubstituted PB (Scheme 24). ${ }^{132}$ With this, they showed that while mechanochemical activation led to $c a$. 95\% conventional and symmetry-allowed disrotatory ring-closing, ca. 5\% conrotatory ring-closing towards the anti-WH product could be observed. This result was confirmed by ab initio molecular dynamics simulations.

Single-molecule force spectroscopy. SMFS emerged as a powerful tool to investigate forces associated with both synthetic and biological macromolecules. ${ }^{133}$ As opposed to bulk material activation, SMFS is distinctly different with regard to achievable strain rates, the isolated physicochemical environment and environmental factors, such as temperature, mechanical vibrations, air currents, or acoustic and electrical noise. This has to be considered when interpreting the timescales on which SMFS experiments are compared to classical mechanochemical activation in solution or in the bulk.

In order to quantify the extent of $\mathrm{WH}$ rule violation by mechanochemical ring-opening and -closing of $g \mathrm{DHCs}$, SMFS was utilized. In one of the approaches, SMFS of three mechanically induced reactions along both their symmetry-allowed and symmetry-forbidden pathways was performed by Martinez, Craig and co-workers. ${ }^{134}$ It was found that the symmetry-forbidden ring-opening reactions of benzocyclobutene (BCB, vide infra), $g \mathrm{DFC}$ and $g \mathrm{DCC}$ required approximately $130 \mathrm{pN}$ less, $560 \mathrm{pN}$ more and $1000 \mathrm{pN}$ more force, respectively, than their corresponding symmetry-allowed counterparts. These results provided the first experimental quantitative benchmarks for mechanically induced anti-WH reactions, while the 
BCB ring-opening was the first demonstration of a forcecoupled symmetry-forbidden reaction that was faster than its force-coupled symmetry-allowed counterpart.

In another work, single-molecule polymer mechanochemistry was utilized to induce the disrotatory outward ring-opening of a Z-dialkyl substituted syn-chloro-gem-chlorofluorocyclopropane (syn-Cl-gCFC). ${ }^{135}$ The forces required to trigger the anti-WH pathway were $c a .200 \mathrm{pN}$ higher than those involved in the $\mathrm{WH}$ compliant process (1290 vs. 1500 pN). The kinetics were complemented by tension trapping experiments, which suggested that the reaction proceeded by the previously established diradical mechanism. Moreover, mechanisms for thermal and mechanical activation of dimethyl-gCFC were proposed (Scheme 25). The methyl groups thermally underwent inward disrotation, during which the electrons of the breaking $\mathrm{C}-\mathrm{C}$ bond were donated to the antibonding orbital of the $\mathrm{C}-\mathrm{Cl}$ bond to assist the scission of the $\mathrm{C}-\mathrm{Cl}$ bond subsequently forming the $E$-alkene product and following the WH rules. Mechanically pulling on the methyl groups forced the rotation outwards, although this disfavoured the cleavage of the Cl-anion, violating the WH rules. During the mechanically activated ring-opening reaction, syn-Cl-gCFC first formed a diradical, which then underwent ion separation to form the $Z$-alkene product.

SMFS was also applied to observe an irreversible extension of a gem-dibromocyclopropane ( $g$ DBC)-functionalized $\mathrm{PB}$ under tension. ${ }^{122}$ The extension of close to $28 \%$ in contour length of the polymer backbone occurred at roughly $1.2 \mathrm{nN}$ and was attributed to the force-induced isomerization of the $g$ DBCs into 2,3-dibromoalkenes (Fig. 5). This rearrangement is valuable for localized stress relief in polymers and polymer networks under load.

SMFS investigations further revealed that the force-induced acceleration of the electrocyclic ring opening of gDCC was sensitive to the stereochemistry of an $\alpha$-alkene substituent on the $g$ DCC. ${ }^{41}$ The force required to open the $E$-alkene-substituted $g$ DCC was found to be $0.4 \mathrm{nN}$ lower than that required in the corresponding $Z$-alkene isomer, despite the effectively identical force-free behaviour of the two isomers as well as the dis-

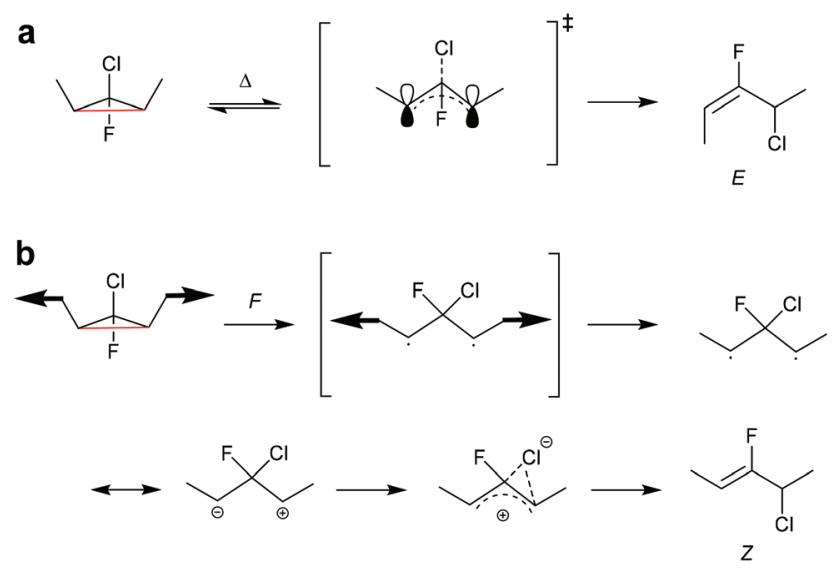

Scheme 25 Mechanisms for (a) thermal and (b) mechanochemical activation of dimethyl-gCFC. ${ }^{135}$
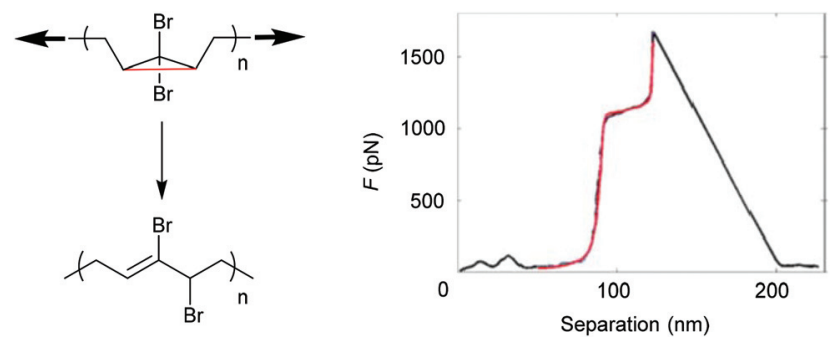

Fig. 5 SMFS indicating the irreversible extension of a $g D B C$-functionalized PB under tension. Reproduced with permission from ref. 122. Copyright 2010 American Chemical Society.

tance between the stereochemical permutation and the scissile bond of the mechanophore. This was termed 'lever arm effect' by Craig and co-workers owed to the greater mechanical advantage for a given applied force that could be gained. ${ }^{126,136}$

Moreover, the mechanochemical activation of $g \mathrm{DFC}$ $Z$-isomer in toluene was investigated by SMFS. ${ }^{137}$ Unlike previous reports in methyl benzoate (MB), ${ }^{134}$ two transitions were observed in the force-extension curves of $Z$ - $g$ DFC polymers in toluene. The first and previously observed transition occurred at $\sim 1300 \mathrm{pN}$, but a second transition was observed at $\sim 1800$ $\mathrm{pN}$ that revealed the partial formation of the $E$ - $g \mathrm{DFC}$ isomer (Fig. 6). This was attributed to competing reactions of the $Z$ -

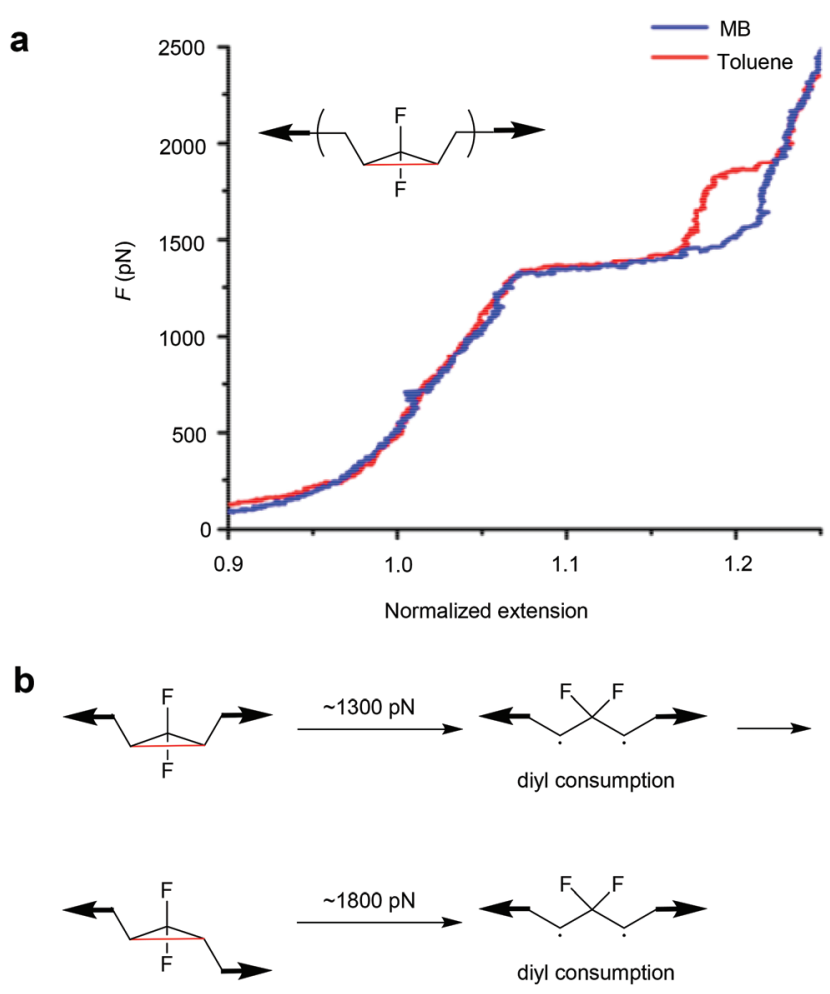

Fig. 6 (a) Representative SMFS force curves of Z-gDFC polymer obtained in MB (blue) and toluene (red). (b) The mechanistic scheme for $Z$-gDFC when the SMFS experiment is performed in toluene. Adapted with permission from ref. 137. Copyright 2016 American Chemical Society. 
$g \mathrm{DFC}$ at the $1300 \mathrm{pN}$ plateau: addition of oxygen to a ringopened diradicaloid intermediate and isomerization of $Z$-gDFC to its $E$ isomer.

Computational simulations. Computational simulations are a potent tool to understand and describe the atomistic details of mechanochemical reactions. As comparable to the modelling of other chemical reactions, a variety of levels of theory being electronic structure based static methods or $a b$ initio molecular dynamics methods can be employed with different levels of precision and computational costliness. For a comprehensive review of these methods the reader is referred to an excellent review of Ribas-Arino and Marx. ${ }^{138}$

Based on computational simulations, Marx and co-workers also confirmed the deviation from the intuitive set of $\mathrm{WH}$ rules when biasing the potential energy surfaces with mechanical force instead of heat or light. They examined the mechanochemical reactivity and force-induced stereochemistry of $g$ DCCs based on ab initio simulations. ${ }^{139}$ By this, they unveiled the mechanisms of force-induced ring-opening of $g$ DCC $Z$-isomer versus E-isomer, rationalizing the puzzling experimental findings described above. ${ }^{120}$ Notably, they discovered an unprecedented complex mechano-stereochemical feature, whereby the ring-opening of $E$-isomers of 2,3-disubstituted $g$ DCCs led to two different diastereomers, with the probabilities of obtaining them depending of the force exerted on the system.

In another study, Marx and co-workers indicated that both the electron-density-based 'atoms in molecules' (AIM) analysis and the complementary Lewis-structure-based 'natural resonance theory' (NRT) decomposition supported the finding that the electronic structures, underlying the dis- and conrotatory ring-opening mechanisms along the mechanochemically distorted reaction pathways, were very similar to those of the respective (WH-allowed and $\mathrm{WH}$-forbidden) thermal pathways. ${ }^{140}$ Concomitantly, they claimed that the WH rules, which were based on electronic structure considerations of certain classes of thermally and photochemically activated reactions, should not be considered to be transferable to the same reactions once mechanochemically activated. Instead, the $\mathrm{WH}$ rules must be complemented by yet to be formulated 'mechanochemical rules'.

They further showed the impact of halogen substitution on the thermally activated ring-opening process followed by halogen migration of $(2 S, 3 S)$-1,1-dihalo-2,3-dimethylcyclopropanes in the case of $\mathrm{F}, \mathrm{Cl}, \mathrm{Br}$ and I distribution. ${ }^{141}$ Surprisingly, the direction of halogen migration in the case of disrotatory ring-opening was qualitatively different for the difluorinated cyclopropane compared with the homologous $\mathrm{Cl}$, $\mathrm{Br}$ and I species. For $g \mathrm{DFC} E$-isomer, the decision was governed by an uphill bifurcation followed by two separate transition states for each migration direction, whereas the disrotatory transition state was first surmounted in the other three cases followed by a downhill bifurcation into the disrotatory products. Thus, chemical substitution was found to qualitatively change the potential energy landscape for the ringopening of cyclopropanes.
In another attempt, which was based on quantum mechanochemical computations at constant external forces, they discovered that the topology of the energy landscape for mechanochemically activated ring-opening of $g$ DFC $E$-isomer was qualitatively different in the high-force regime compared with low-forces down to the thermal limit. They showed that both uphill and downhill bifurcations being pre- and post-transition state features, respectively, were shifted continuously by applying external mechanical forces as typically generated by ultrasonication. These findings depicted an approach towards steering the selectivity of chemical reactions in favour of the desired products by mechanochemical activation.

\section{Applications}

Mechanochemical reinforcement and dissipation. $g \mathrm{DBC}$ was employed in the $Z$-form for mechanochemically induced reinforcement of a polymer and another investigation suggested that this might as well be carried out with gDCC as the ring-opening reaction could be gated and hence regulated with regard to its activity (the principle of mechanochemical gating was explained above). ${ }^{55,142}$ For this, the bulk activation of $g$ DBC mechanophores, embedded along a PB scaffold to the corresponding 2,3-dihaloalkenes, was analysed in response to extrusion. $^{142}$ In the presence of a benzyltriethylammonium chloride salt this not only led to ring-opening but also to subsequent secondary bond formation reactions with over $25 \times$ more covalent bonds being formed than cleaved. This suggested that force-induced bond formation could be a viable strategy for engineering useful material properties, such as autonomous reinforcement. Beyond secondary bond formation, Boulatov, Craig and co-workers used a cyclobutane mechanophore as a gate to regulate the activation of a second mechanophore, gDCC, resulting in a mechanochemical cascade reaction and dissipating force through sacrificial bond scission. $^{55}$

Quantification of bond strength. Further studies used polymer sonochemistry as a tool for quantifying the relative mechanical strength and force distributions within scissile polymers. $^{143}$ In particular, the mechanochemistry of $g$ DCCbased polymers were investigated. Insights were obtained by monitoring mechanochemical bond transformation as a function of initial polymer molar mass and sonication conditions and revealed that the competition between $g \mathrm{DCC}$ activation and polymer chain scission was invariant to sonication power, temperature, polymer concentration and solvent, but was sensitive to initial polymer molar mass.

In further efforts, Craig and co-workers investigated the relative mechanical strengths of polymers bearing comparatively weak scissile covalent bonds. ${ }^{144}$ Multiple scissile bonds and non-scissile mechanophores were embedded along polymer backbones and stretched by ultrasonication. Thereupon, the non-scissile mechanophores were activated beginning from the centre of the chain radiating outwards until a scissile bond cleaved. The ratio of non-scissile mechanophore activation to bond scission thus provided a measure of the mechanical strength of the weak scissile bond. This meth- 


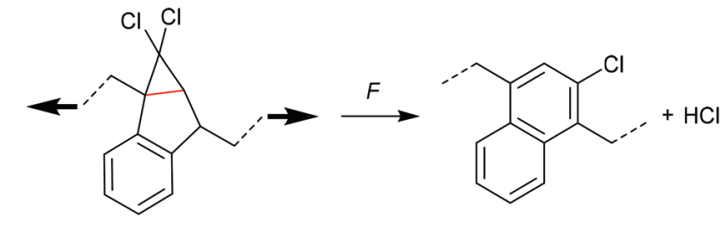

Scheme $26 \mathrm{HCl}$ release from $\mathrm{gDCC}$-substituted indene mechanoacid generator.

odology was lately used to estimate the mechanical strength of other weak bonds including ferrocene and ruthenocene. ${ }^{145,146}$

Mechanoacid generator. Diesendruck, Moore and coworkers developed a $g$ DCC-substituted indene, which released $\mathrm{HCl}$ in a downstream reaction upon force-activation by aromatization (Scheme 26). ${ }^{147}$ This mechanophore acted, analogously to a photoacid generator, as simple catalyst for chemical alterations in materials under force, i.e. a mechanoacid generator. The mechanophore was used as a crosslinker in PMA and samples loaded by uniaxial compression. The generation of acid was confirmed by exposing a piece of insoluble compressed polymer to a $\mathrm{pH}$ indicator solution and paved the way to the activation of productive chemistry with mechanical force. Most notably, this development was recently improved by Craig and co-workers employing a benzylic $g$ DCC and an oxime sulfonate as mechanophore. ${ }^{148}$

\section{4-Electron electrocyclic ring-opening reactions}

\section{Benzocyclobutene}

Chronologically, one of the first reported mechanophores studied in detail was the benzocyclobutene moiety, which is able to undergo a 4-electron electrocyclic ring-opening reaction upon application of mechanical force (Scheme 27). Up to today, several works were published underlining the general feasibility of this motif as mechanophore. ${ }^{11,149-151}$ However, the first benzocyclobutene-based mechanophore was designed and synthetized by Moore, White, Sottos and co-workers in 2007. ${ }^{152}$ This first experimental work did not include any mechanistic study, but rather focussed on the validation of benzocyclobutene mechanochemical activity in solution when integrated in the centre of a linear polymer chain.

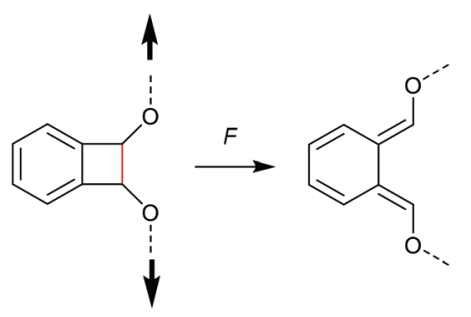

Scheme 27 Mechanochemically induced 4-electron electrocyclic ringopening reaction of benzocyclobutene.
Benzocyclobutene is non-scissile and hence comparative molar mass analyses were not useful to prove the mechanochemical activity of this motif. However, a maleimide-pyrene conjugate undergoing a DA reaction with the mechanochemically generated diene structure allowed post-functionalization of the force-activated moiety with a chromophore and hence quantitative evaluation. This confirmed the successful mechanochemical activation of this motif and gave rise to further and more detailed studies on this scaffold, especially concerning the stereochemical outcomes in relation to the $\mathrm{WH}$ rules.

\section{Mechanistic considerations}

As for all pericyclic reactions, the $\mathrm{WH}$ rules describe the thermal and photochemical 4-electron electrocyclic ringopening reactions allowing the prediction of the stereochemical outcome based on the configurations of the reactants. ${ }^{15}$ For ring-opening or ring-closing, the concerted mechanism can follow a conrotatory or a disrotatory pathway, depending on the symmetry of the frontier orbitals involved in the process. The distinction is straightforward and based on the relative position of the orbital phases that can overlap in a constructive manner. Thermal 4-electron electrocyclic reactions follow a conrotatory pathway while photochemically a disrotatory mechanism is favoured. The stereochemical identity of the reaction products is hence a consequence of the symmetry of the involved orbitals and is easy to predict adhering to Scheme 28 .

With regard to the WH rules, mechanistic studies on the mechanochemically induced ring-opening of benzocyclobutene were carried out focusing on the configuration of the involved stereoisomers. ${ }^{134,136,152-155}$ Notably, stereoisomers that were symmetry-forbidden by the $\mathrm{WH}$ rules, were accessi-

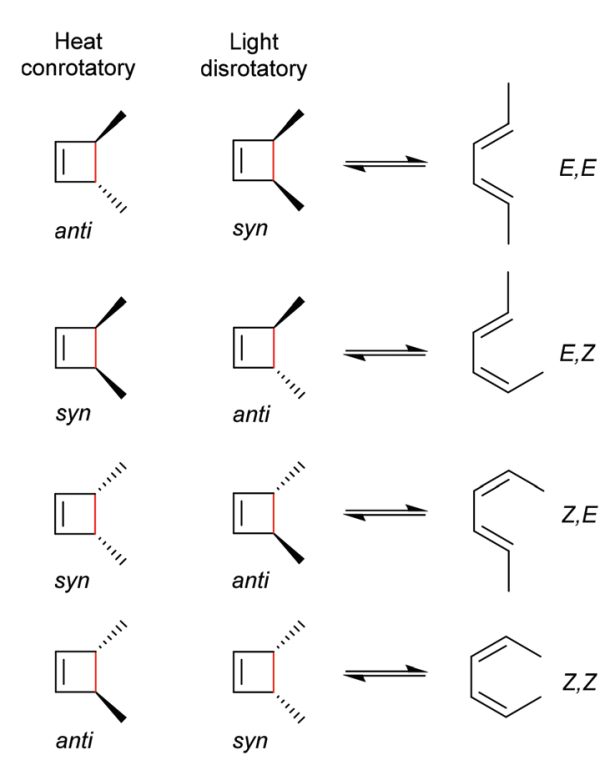

Scheme 28 Thermally and photochemically allowed pathways of cyclobutene ring-opening according to the respective reactant configurations and the $\mathrm{WH}$ rules. 


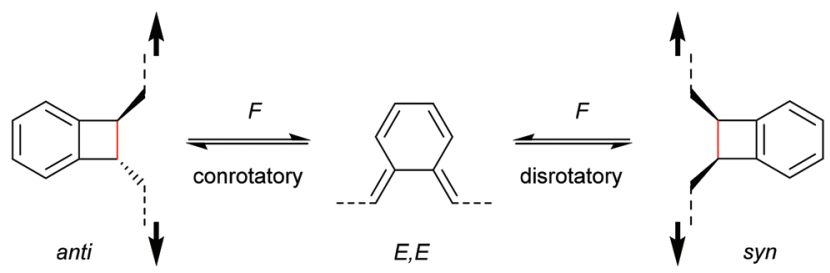

Scheme 29 Stereochemistry of mechanochemically induced 4-electron electrocyclic ring-opening of benzocyclobutene.

ble by force. For example, both syn- and anti-cyclobutene isomers yield the E,E-diene mechanochemically (Scheme 29). It was argued that elongation of the polymer termini in opposite directions produces a transition state geometry in which the two substituents are as far as possible away from each other, i.e. the E,E-diene. Hence, while employing an anti-reactant a conrotatory pathway in agreement with the WH rules for thermal reactions was followed, employing a syn-reactant a disrotatory pathway conforming to the WH rules for photochemical reactions entailed. ${ }^{15}$

Although no experimental evidence about the concerted (or diradical) character of the underlying ring-opening mechanism exists, computational simulations found that the force-coupled transition state energy levels inverted compared to the thermal pathway and that the disrotatory ringopening becomes more accessible with the application of force. $^{156}$

Notably, Craig and co-workers found that structural modification enhanced the mechanochemical activity of the benzocyclobutene mechanophore. They observed that substitution of the motif with an $\alpha$-alkene lowered the force required for the ring-opening process. ${ }^{136}$ This is in analogy to the 'lever arm effect' discussed above with regard to gDHCs. ${ }^{41,126}$

Mainly two different computational simulation techniques were used with regard to the mechanical activation of benzocyclobutene: AISMD (ab initio steered molecular dynamics) and CoGEF (constrained geometry to simulate external force). ${ }^{16,156-162}$ Both examples aimed to characterize the forcemodified PES for the ring-opening pathway. Martinez and coworkers were the first to rationalize experimental observations using AISMD simulations. ${ }^{156}$ They determined the highest energy difference between the force-free and the force-dependent PES for the conrotatory pathway when ring-opening from the anti-isomer and for the disrotatory pathway when ringopening from the syn-isomer. This results in acceleration of the ring-opening towards the $E, E$-product from both the synand anti-isomers when mechanical force is applied. In addition, Marx and co-workers exploited CoGEF simulations to gain insight into transmission mechanisms of directional forces to the benzocyclobutene scaffold and its associated ring-opening. ${ }^{157}$ They suggested that a stepwise mechanism involving a diradical intermediate could be excluded and a concerted mechanism would be the most plausible for both syn- and anti-isomers. ${ }^{16,158}$

\section{6-Electron electrocyclic ring-opening reactions}

\section{Spiropyran to merocyanine isomerization}

The 6-electron electrocyclic ring-opening of spiropyran (SP) to merocyanine (MC) via temperature, light or $\mathrm{pH}$ is among the most studied 'chromic' transformations in the literature. ${ }^{163,164}$ Mechanochromic behaviour of individual small SP molecules was first shown by Tipikin in grinding experiments. ${ }^{165}$ Based on these initial findings, Moore and co-workers incorporated SP into the centre of linear PMA chains and investigated the polymer mechanochemical activation to MC in ultrasonication experiments (Scheme 30). ${ }^{150}$ The ring-opening was monitored via UV-Vis spectroscopy and showed absorption changes from a colourless to a pink solution. The activation is reversible by exposure to ambient light or heat. Since then, SP was used as the most successful mechanophore with regard to publication numbers in a variety of materials to investigate the force-related properties of, e.g., polyacrylates, ${ }^{7,150,166-173}$ polymethacrylates, ${ }^{174,175,176-183,184}$ polyurethanes, ${ }^{185-193}$ polydimethylsiloxane (PDMS) ${ }^{194-202}$ polystyrene, ${ }^{203}$ polycaprolacton, ${ }^{204,205}$ polyolefins, ${ }^{206}$ polycarbonate, ${ }^{207}$ polyarylenes $^{208}$ and different copolymers. ${ }^{209-216}$

Regiochemical effects on mechanochemical SP activation were investigated by varying substitution patterns. Based on these patterns, it was possible to distinguish between several SP variants. For mechanochemical activation, it was found that it was critical to attach the polymer chains on opposing sides of the spiro $\mathrm{C}-\mathrm{O}$ junction. ${ }^{166}$ If both polymer chain attachment points were located on the indole side, the SP could not be activated by force, yet still functioned as photoswitch (Scheme 31). ${ }^{203}$ Three widely researched mechanochemically active SPs were described in the literature: in SP1 the attachment points are located at the $5^{\prime}$ position of the indole side and position 8 of the benzopyran side. ${ }^{150,166}$ In SP2 the polymer chains are attached via a functionalisation of the indole nitrogen and the 8 position of the benzopyran. ${ }^{204}$ SP3 substitutes the nitro group of the benzopyran side with a polymer chain attachment point. ${ }^{217}$ SP1 and SP2 were shown to be force- and light-responsive while the absence of the electron withdrawing nitro group was proven to inhibit photoreactivity in SP3. Recovery time after ring-opening for SP3 was quite short ( $\sim 30 \mathrm{~s})$ compared to longer thermal ring-closing periods in the cases of SP1 and SP2 ( 40 min). ${ }^{170}$

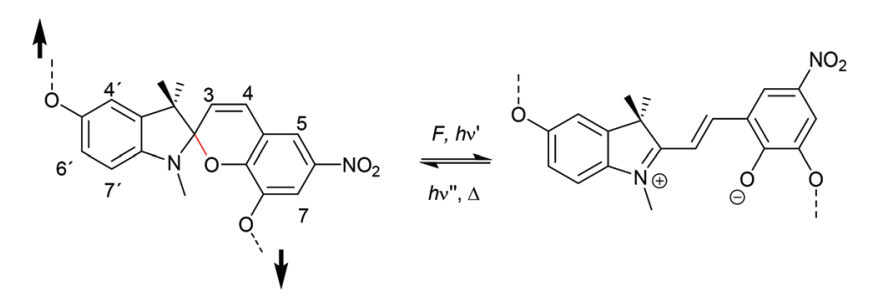

Scheme 30 Mechanochemical isomerization of spiropyran to merocyanine. 


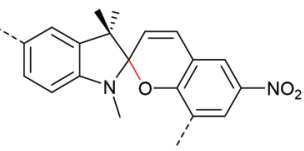

SP1

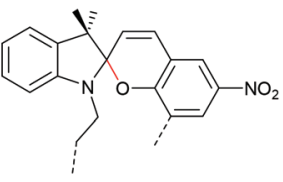

SP2

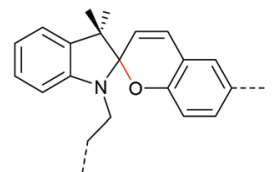

SP3

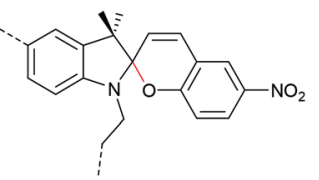

mechanochemically inactive

Scheme 31 Mechanochemically active and inactive SP derivatives depending on polymer chain substitution patterns.

Craig and co-workers investigated the mechanochemical reaction rate of SP1 and SP2 to their respective MCs by AFM SMFS. ${ }^{218}$ For this, macrocycles incorporating SP were copolymerized with 9-oxabicyclo[6.1.0]non-4-ene (epoxy-COD) and single molecule force-extension curves were recorded through approach/withdraw cycles at varying velocities. These show the characteristic conversion of SP to MC at $\sim 260 \mathrm{pN}$ for SP1 and $\sim 240$ pN for SP2. In addition, computational simulations revealed that SP1 undergoes isomerization to MC easier than SP2 in absence of force, but under mechanochemical activation under SMFS conditions the force threshold of SP1 is on average $10 \%$ higher (Fig. 7 ).

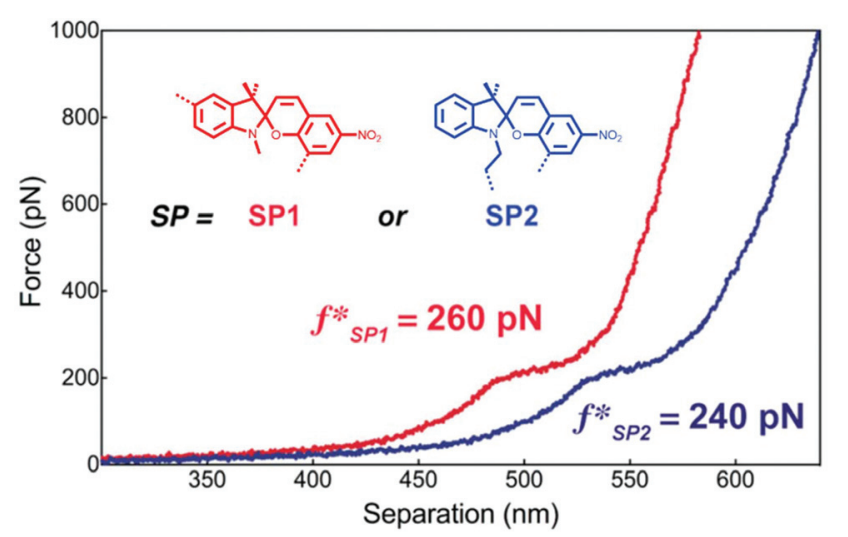

Fig. 7 Representative single molecular force-extension curves of macrocycles incorporating SP1 or SP2 copolymerized with epoxy-COD. Adapted with permission from ref. 218. Copyright 2015 American Chemical Society.
Based on this work, Sottos, White, Moore and co-workers investigated the mechanical activation of SP1 and SP2 as crosslinkers in bulk PDMS under mechanical load with the help of computational calculations and in situ fluorescence measurements. ${ }^{219}$ They could not find a significant difference for the stress or strain required for the activation of the two regioisomeres in the polymer matrix (Fig. 8). Moreover, isomerization rates for SP to MC conversion and vice versa were nearly identical under macroscopic tensile stress. It was hence concluded that the difference in the pulling geometry between SP1 and SP2 had only a negligible influence on the mechanochemical activation in bulk polymeric materials because of the intrinsic complexity of these macroscopic systems.

Qiao and co-workers systematically investigated the geometric and electronic effects of SPs under compression and tension and determined that geometry dominated the mechanochromic responses in dependence of varying attachment points over electronic effects. ${ }^{220}$ For this, they synthesized a novel SP mechanophore (SP4) with a combination of all attachment points of SP1 and SP2 (Scheme 32). In conjunction with SP1 and SP2, SP4 was incorporated into PDMS and the colour change in mechanical tests was investigated. They monitored a notable variation in the RGB intensities of the three SP after activation to MC by force followed by relaxation back to the SP form. With the help of DFT calculations they contributed these colour changes towards different $\mathrm{MC}$ isomers and hypothesized different path for MC isomers of SP1 and SP2 under force and relaxation (Scheme 33). SP1 reacts and recovers directly to the $Z, Z, Z$-isomer with a short interatomic distance whereas SP2 reacts to the $Z, Z, E$-isomer, which relaxes to the $Z, Z, Z$-isomer, followed by recovery to SP.
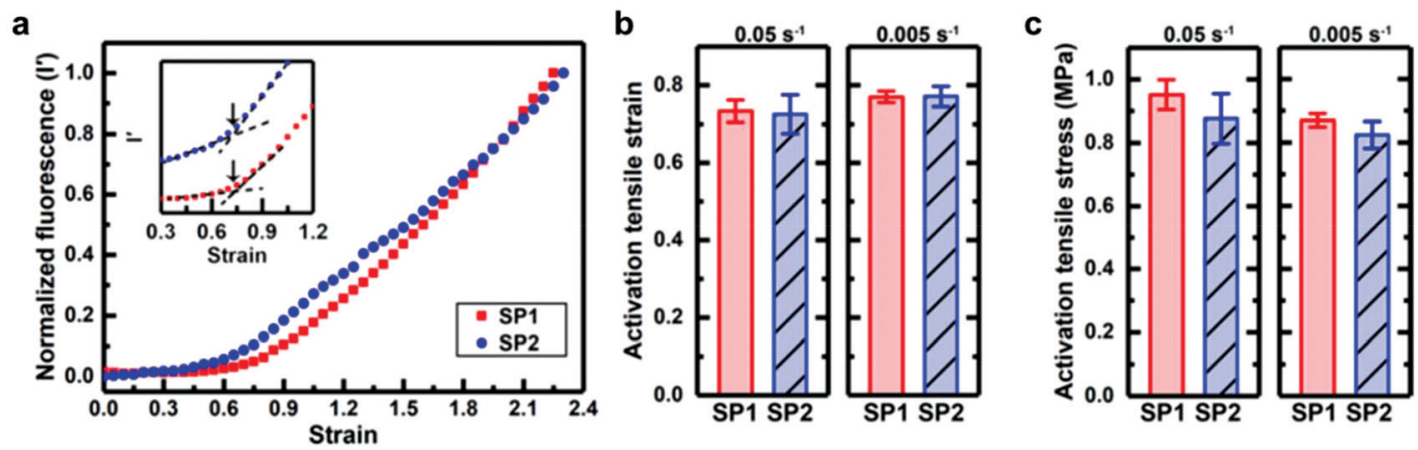

Fig. 8 Activation behaviour of SP1 or SP2 incorporated in PDMS under tension: comparison of (a) the normalized fluorescence intensity as a function of strain at a strain rate of $0.05 \mathrm{~s}^{-1}$; (b) the onset of activation strain; (c) the activation stress. ${ }^{219}$ Reprinted with permission from ref. 219 . Copyright 2018, American Chemical Society. 


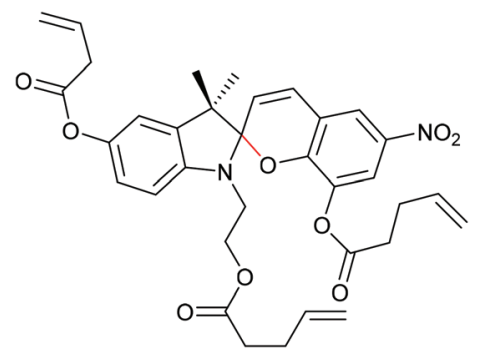

Scheme 32 SP4 crosslinker combining the polymer attachment points of SP1 and SP2. ${ }^{220}$
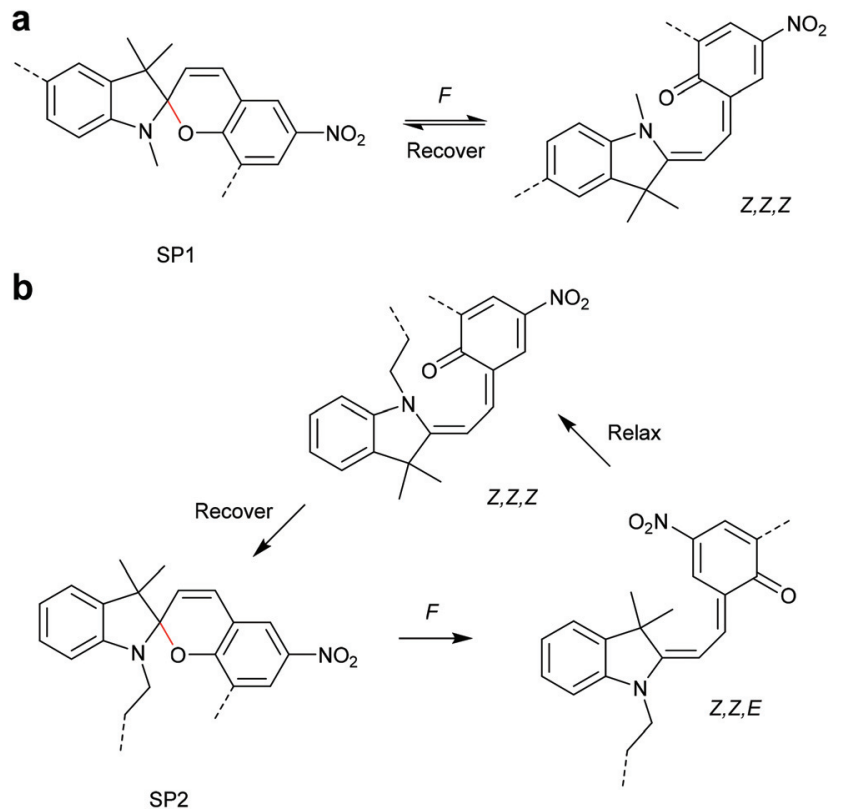

Scheme 33 Hypothesized (a) SP1 and (b) SP2 activation and relaxation pathways by Qiao and co-workers. ${ }^{220}$

Although SP4 is electronically more related to SP1 because of the slightly electron donating vinyl ester, SP4 behaves comparable to SP2 showing a hypsochromic shift during and after mechanical loading, which is most likely contributed to by the attachment point in the $1^{\prime} N$-position.

Roessler and Zimmerman previously used GSM computations to locate reaction paths and products for SP1. ${ }^{95}$ In their study, they identified two merocyanine products, the $Z$ - and $E$-isomer (Scheme 34 ). At forces $<2 \mathrm{nN}$ the $Z$-product was found, but at higher forces the ring-open structure isomerized to the $E$-structure without an energy barrier. With increased applied force the activation barrier for the ring opening decreased roughly linearly (slope of $-5.9 \mathrm{kcal} \mathrm{mol}^{-1} \mathrm{nN}^{-1}$ ) as $Z$ - and $E$-products had similar transition states (TS) and the $Z$ $E$-isomerisation took place after a rate limiting ring-opening TS.

Craig and co-workers investigated the effect of the polymer attachment point on the benzopyran-ring for three SP regioisomers. ${ }^{221}$ SP derivatives with one attachment point at the

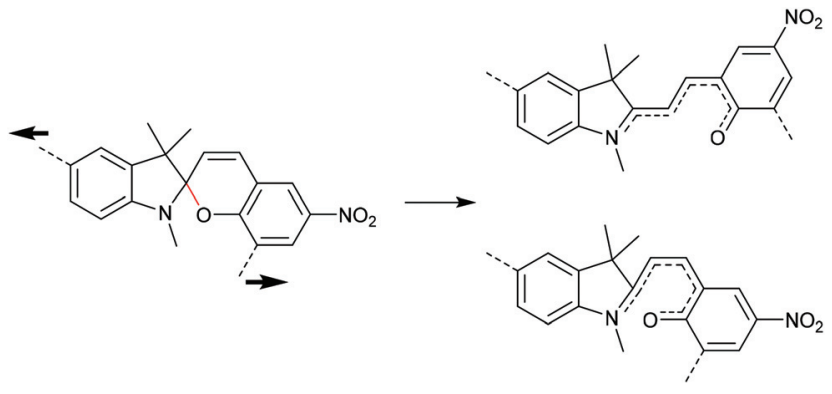

Scheme $34 Z$ - and E-isomers of merocyanine for the force induced SP1 reaction, according to computational simulations by Roessler and Zimmermann.

indoline fragment and the other one in ortho- $(\mathrm{SP}(o))$, meta$(\mathrm{SP}(m))$ or para- $(\mathrm{SP}(p))$ position of the spirocyclic $\mathrm{C}-\mathrm{O}$ bond were incorporated in PDMS films and their colour change was studied under tensile load. RGB images were analysed and the intensity in blue and green channels (B/G ratio) was used to evaluate the mechanophore activity. The extrapolated strain onset for detectable activation of all three regioisomeres occurred at $c a .90 \%$ uniaxial strain in bulk PDMS. At higher strains $(90-135 \%)$ the relative activation of $\operatorname{SP}(o) / \mathrm{SP}(m) / \mathrm{SP}(p)$ was estimated through the normalized increase in $\mathrm{B} / \mathrm{G}$ value as $3.2: 1.6: 1$, which was consistent with the expected relative response of the isolated isomers (Fig. 9). Although their results suggested that the mechanochemical activation was determined foremost by the network structure or was too small to detect, they discussed that in case of individual mechanophores the onset activation should follow the same trend (SP $(o)>\operatorname{SP}(m)>\operatorname{SP}(p))$, because electronic effects are modest and therefore the geometric effect should dominate.

The effect of substituents with different electronegativity in the para-position to the spirocyclic $\mathrm{C}-\mathrm{O}$ bond in SP2 was recently studied employing SMFS. ${ }^{222}$ SP2 derivatives with para $\mathrm{H}, \mathrm{Br}$ or $\mathrm{NO}_{2}$ were subjected to force and the change in contour length was measured (Fig. 10). Each SP derivative showed a different critical force for the conversion of SP to MC dependent on the electronegativity of the substituent. Lower electronegativity of the substituent translated to a higher necessary transition force $f^{*}: \mathrm{H}(410 \mathrm{pN})>\mathrm{Br}(360 \mathrm{pN})>\mathrm{NO}_{2}$ $(240 \mathrm{pN})$ because a largely heterolytic and polar transition state in the mechanochemical reaction was stabilized by electron withdrawing groups in the para $\mathrm{C}-\mathrm{O}$ position.

\section{Spirothiopyran to thiomerocyanine isomerization}

The sulphur derivative to SP spirothiopyran (STP) was also shown to undergo thermo- and photoactivated isomerization to thiomerocyanine (TMC), which is reversible by visible light. ${ }^{223,224}$ Boulatov and co-workers studied the mechanochemistry of STP. ${ }^{225}$ They incorporated multiple STP moieties into the backbone of polyester and polyurethane and showed the STP activation via sonication or irradiation at $365 \mathrm{~nm}$ (Scheme 35). The light-yellow polymer solution turned green 
a

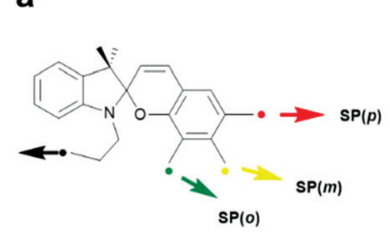

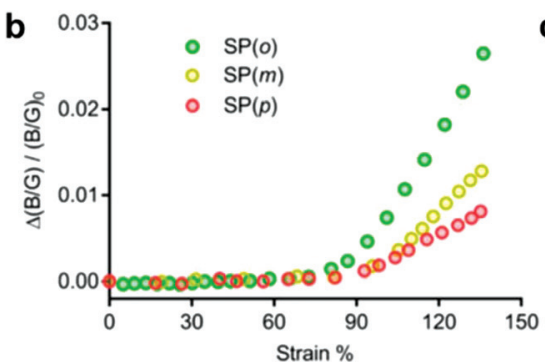

C

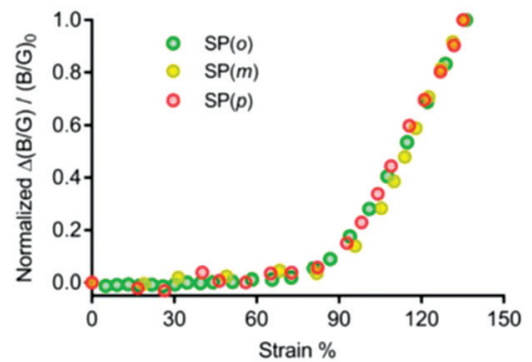

Fig. 9 (a) Spiropyran regioisomers with force handles in ortho-, meta- and para-position towards the spiro C-O bond. (b) Alteration of B/G intensity. (c) Alteration of B/G intensity normalized to the value at $135 \%$ strain. ${ }^{221}$ Adapted with permission from ref. 221 Copyright 2018 American Chemical Society.

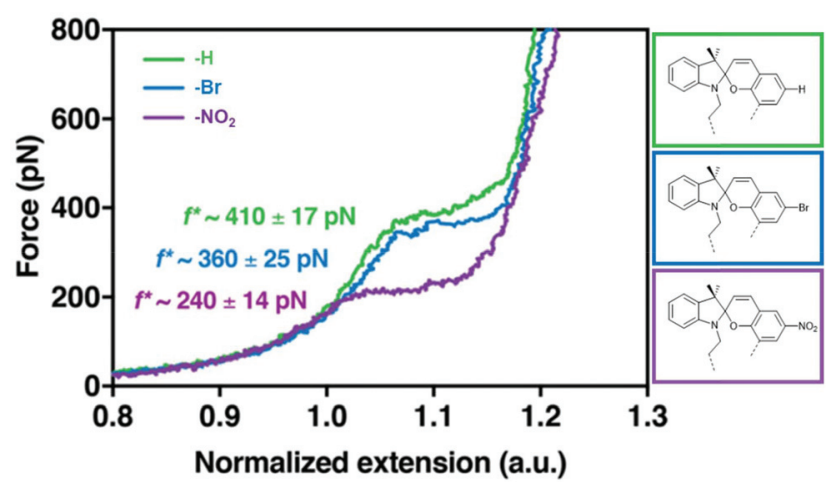

Fig. 10 SMFS curves for SP2 derivatives with para- $\mathrm{H},-\mathrm{Br}$ or $-\mathrm{NO}_{2}$ and their transition force $f^{\star} .{ }^{222}$ Adapted with permission from ref. 222. Copyright 2018 American Chemical Society.

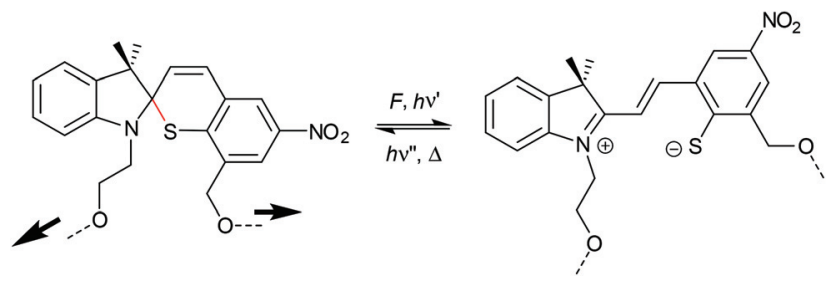

Scheme 35 Mechanochemical isomerization of spirothiopyran to thiomerocyanine.

and a new absorption band at $635 \mathrm{~nm}$ indicated the isomerization to TMC.

\section{Naphthopyran to merocyanine isomerization}

Analogously to SP, naphthopyran (NP) mechanophores react to MC via a 6-electron electrocyclic ring-opening reaction. ${ }^{48,226-228}$ Concomitantly to SP, the polymer attachment point for the mechanochemical activation of NP is crucial. Moore and co-workers investigated three different NP derivatives with varying polymer attachment points and determined that only the attachment of polymer chains to the 5-positon led to mechanochemical activity (Fig. 11). ${ }^{226}$ Regioisomers with substituents in 8- and 9-position were mechanochemically inactive because of disadvantageous align-
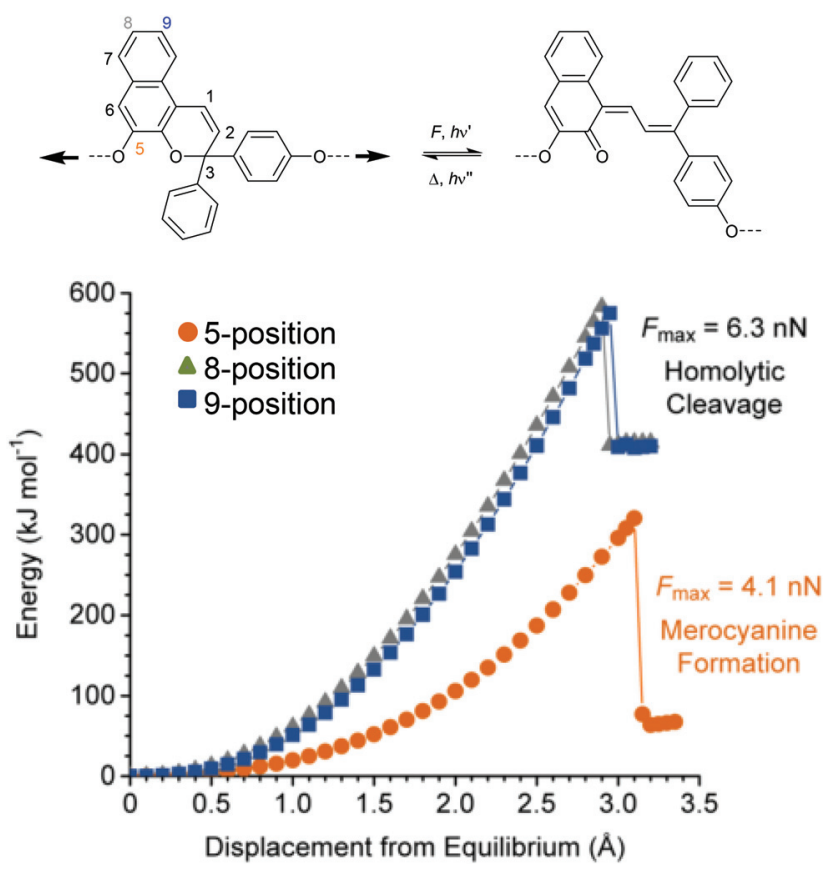

Fig. 11 6-Electron electrocyclic ring-opening of NP under mechanical force. (a) Reaction scheme and (b) DFT calculations for three NP regioisomers. Cleavage of $\mathrm{C}-\mathrm{O}$ pyran bond is only predicted for the NP with polymer attachment at the 5-position. ${ }^{226}$ Adapted with permission from ref. 226. Copyright 2016 American Chemical Society.

ment of the $\mathrm{C}-\mathrm{O}$ pyran bond with the direction of the externally applied force.

\section{Rhodamine}

The activation of rhodamine ( $\mathrm{Rh}$ ) derivatives is another wellresearched electrocyclic ring-opening reaction in which the non-fluorescent spirolactam opens to the strongly fluorescent amide. $^{229}$ Mechanochromic behavior of single organic molecule Rh was first shown in shearing and grinding experiments. ${ }^{230,231}$ Based on these results, Jia and co-workers synthesized a Rh-mechanophore, incorporated it into polyurethane (PU) films and sensitivity of the material towards mechanical force and UV light was shown (Scheme 36). ${ }^{232}$ The ring opening reaction from the twisted spirolactam 

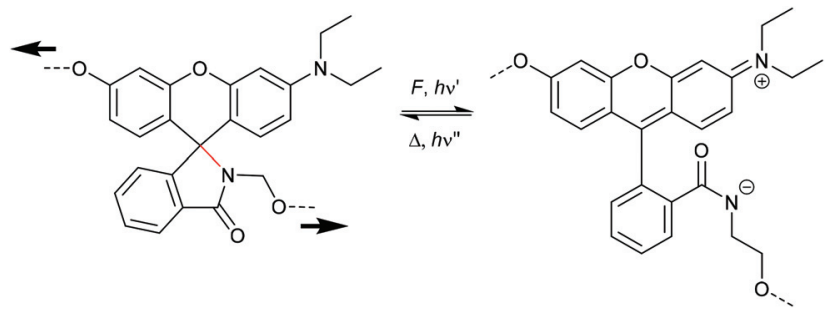

Scheme 36 Mechanochemical isomerization of rhodamine to the planarized zwitterionic amide. ${ }^{232}$

towards the planarized zwitterion was monitored via UV-Vis and fluorescence spectroscopy and showed a distinct color change from dark blue to reddish, as well as a new fluorescent band at $550 \mathrm{~nm}$. Similar to $\mathrm{SP}$, the mechanophore activation was reversible at ambient temperature or by heating. In following studies the $\mathrm{pH}$ responsiveness of $\mathrm{Rh}$ mechanophores was demonstrated. ${ }^{233}$ An acidic $\mathrm{pH}$ activates the mechanophore, whereas basic pH promotes the cyclization reaction.

Bai and co-workers synthesized a three armed Rh-mechanophore crosslinker for the incorporation in elastomeric networks (Scheme 37, left). ${ }^{234}$ In their experiments, they showed a yellow fluorescence after the release of force. Theoretical calculations revealed that a large dipole moment in the zwitterionic $\mathrm{Rh}$ leads to the formation of a bent geometry with a $\mathrm{C}-\mathrm{C}-\mathrm{O}$ bond angle of $134^{\circ}$. Upon breaking of the $\mathrm{C}-\mathrm{N}$ bond in the twisted spirolactam this $\mathrm{C}-\mathrm{C}$ bond was bent and the conformation of the zwitterion was planarized to facilitate the delocalization of the $\pi$ electrons in the phenyl ring to that of the xanthene resulting in a bathochromic shift. After relaxation, the zwitterion immediately changed back to the bent geometry resulting in a hypsochromic shift.

In this work, they further introduced a control Rh mechanophore with both polymer attachment points located on the xanthenes which is mechanochemically inactive because force cannot be transferred across the spiro $\mathrm{C}-\mathrm{O}$ bond (Scheme 37, middle). Another control two-armed Rh mechanophore with attachment points across the $\mathrm{C}-\mathrm{O}$ junction (Scheme 37, right) showed expected activation but the bathochromic shift and the activated fraction were lower compared to the three armed mechanophore. ${ }^{234,235}$

\section{Conclusions and outlook}

Dissociative pericyclic reactions have proven themselves excellent candidates for their force-activation in the context of polymer mechanochemistry. While plenty of uncertainties about the underlying mechanisms and design rationales remain to be resolved, some overarching conclusions can be drawn from the existing body of literature:

1. Polymer mechanochemical pericyclic reactions mostly do not follow the established concerted mechanisms their smallmolecular counterparts do. In many cases it was shown, both experimentally and by computational simulations, that diradical or rarely ionic transition states dominate the reaction pathway. While it is arguable whether these reactions thus formally can be considered pericyclic, discussing them in line with their heat- and light-induced counterparts is reasonable as they offer access to reaction products that are unobtainable according to the Woodward-Hoffmann rules.

2. As force is a directional vector quantity, the attachment points, identity and size of the substituted polymer chains transmitting the force to the molecular motif are of paramount importance. Empirically, polymer mechanochemical pericyclic reactions require the polymer chains to be attached in the vicinity or at the position of the atoms that are directly involved in the bond rearrangement. More generally expressed, this means that the force vector must be aligned with the reaction coordinates.

3. Care must be taken when investigating new motifs, as the debate over the 1,2,3-triazoles as mechanophores impressively demonstrates. Inferring mechanochemical rates from GPC elugrams, which can rarely differentiate selective from non-selective scission, cannot be considered sufficient proof for a successful polymer mechanochemical pericyclic reaction. The reaction products need to be identified unequivocally or transition states derived indirectly by trapping. This holds particularly true for non-scissile motifs where GPC analyses become progressively impractical.

While we thus begin to understand the polymer mechanochemistry of pericyclic reactions and can retrospectively rationalize their outcomes, we still lack a powerful and intuitive set of rules to predict the behaviour of novel motifs within a confined set of reaction conditions. Although theoretical frameworks for examining force-dependent reaction mechanisms<smiles>C=CC(=O)OCCN(CC)c1cc2c(cc1C)C1(c3cc(N(CC)CCOC(=O)C=C)c(C)cc3O2)c2cc(C)c(N(CC)CCOC(=O)C=C)cc2C(=O)N1CCOC(=O)C=C</smiles><smiles>C=CC(=O)OCCN(CC)c1cc2c(cc1C)C1(c3cc(N(CC)CCOC(=O)C=C)c(N(CC)CCOC(=O)C=C)cc3O2)c2ccccc2C(=O)N1CCCC</smiles><smiles>C=CC(=O)OCCC1N(CCOC(=O)C=C)C(=O)C12c1cc(C)c(NCC)cc1Oc1cc(N(CC)CCOC(=O)C=C)c(C)cc12</smiles>

Scheme 37 Three-armed Rh-mechanophore (left) and control Rh-mechanophores (middle and right). 
exist, their application and development needs to be furthered alongside their force-free counterparts. Next to the realization of exciting new applications and functions using force in materials, this will be a major challenge and obligation for researchers involved in this exhilarating field in the future.

\section{Conflicts of interest}

The authors declare no competing financial interest.

\section{Acknowledgements}

R. G., D. C. and C. B. are grateful for support by a FreigeistFellowship of the Volkswagen Foundation (92888). E. I.-N. acknowledges financial support from the European Commission (EUSMI, 731019).

\section{References}

1 S. L. Craig, Nat. Chem., 2017, 9, 1154-1155.

2 W. Kauzman and H. Eyring, J. Am. Chem. Soc., 1940, 62, 3113-3125.

3 G. S. Hammond, J. Am. Chem. Soc., 1955, 77, 334-338.

4 M. K. Beyer and H. Clausen-Schaumann, Chem. Rev., 2005, 105, 2921-2948.

5 G. Kaupp, CrystEngComm, 2009, 11, 388-403.

6 D. Tan and F. García, Chem. Soc. Rev., 2019, 48, 22742292.

7 B. A. Beiermann, S. L. B. Kramer, J. S. Moore, S. R. White and N. R. Sottos, ACS Macro Lett., 2012, 1, 163-166.

8 H. Yan, F. Yang, D. Pan, Y. Lin, J. N. Hohman, D. SolisIbarra, F. H. Li, J. E. P. Dahl, R. M. K. Carlson, B. A. Tkachenko, A. A. Fokin, P. R. Schreiner, G. Galli, W. L. Mao, Z.-X. Shen and N. A. Melosh, Nature, 2018, $554,505-510$.

9 R. Groote, R. T. M. Jakobs and R. P. Sijbesma, Polym. Chem., 2013, 4, 4846-4859.

10 G. S. Kochhar, A. Bailey and N. J. Mosey, Angew. Chem., Int. Ed., 2010, 49, 7452-7455.

11 C. L. Brown and S. L. Craig, Chem. Sci., 2015, 6, 2158-2165.

12 M. M. Caruso, D. A. Davis, Q. Shen, S. A. Odom, N. R. Sottos, S. R. White and J. S. Moore, Chem. Rev., 2009, 109, 5755-5798.

13 T. J. Kucharski and R. Boulatov, J. Mater. Chem., 2011, 21, 8237-8255.

14 J. Li, C. Nagamani and J. S. Moore, Acc. Chem. Res., 2015, 48, 2181-2190.

15 R. Hoffmann and R. B. Woodward, Acc. Chem. Res., 1968, 1, 17-22.

16 J. Ribas-Arino, M. Shiga and D. Marx, Angew. Chem., Int. Ed., 2009, 48, 4190-4193.

17 N. De Souza, Nat. Methods, 2012, 9, 873-877.

18 M. Dal Molin, Q. Verolet, S. Soleimanpour and S. Matile, Chem. - Eur. J., 2015, 21, 6012-6021.
19 S. Akbulatov and R. Boulatov, ChemPhysChem, 2017, 18, 1418.

20 S. Garcia-Manyes and A. E. M. Beedle, Nat. Rev. Chem., 2017, 1, 2397-3358.

21 G. De Bo, Chem. Sci., 2017, 9, 15-21.

22 N. Willis-Fox, E. Rognin, T. A. Aljohani and R. Daly, Chem, 2018, 4, 2499-2537.

23 M. Stratigaki and R. Göstl, ChemPlusChem, 2020, DOI: 10.1002/cplu.201900737.

24 M. J. Kryger, M. T. Ong, S. A. Odom, N. R. Sottos, S. R. White, T. J. Martinez and J. S. Moore, J. Am. Chem. Soc., 2010, 132, 4558-4559.

25 Z. S. Kean, A. L. Black Ramirez, Y. Yan and S. L. Craig, J. Am. Chem. Soc., 2012, 134, 12939-12942.

26 Z. S. Kean, G. R. Gossweiler, T. B. Kouznetsova, G. B. Hewage and S. L. Craig, Chem. Commun., 2015, 51, 9157-9160.

27 C. Chung, Y. Roh, S. Cho and J. Kim, Chem. Mater., 2004, 16, 3982-3984.

28 S. Y. Cho, J. G. Kim and C. M. Chung, Sens. Actuators, B, 2008, 134, 822-825.

29 S.-Y. Cho, J.-G. Kim, S.-Y. Oh and C.-M. Chung, Macromol. Res., 2010, 18, 212-214.

30 H. M. Klukovich, Z. S. Kean, S. T. Iacono and S. L. Craig, J. Am. Chem. Soc., 2011, 133, 17882-17888.

31 B. Koo, A. Chattopadhyay and L. Dai, Comput. Mater. Sci., 2016, 120, 135-141.

32 M. F. Pill, K. Holz, N. Preußke, F. Berger, H. ClausenSchaumann, U. Lüning and M. K. Beyer, Chem. - Eur. J., 2016, 22, 12034-12039.

33 Z. S. Kean, Z. Niu, G. B. Hewage, A. L. Rheingold and S. L. Craig, J. Am. Chem. Soc., 2013, 135, 1359813604.

34 M. J. Kryger, A. M. Munaretto and J. S. Moore, J. Am. Chem. Soc., 2011, 133, 18992-18998.

35 R. Groote, B. M. Szyja, F. A. Leibfarth, C. J. Hawker, N. L. Doltsinis and R. P. Sijbesma, Macromolecules, 2014, 47, 1187-1192.

36 M. J. Robb and J. S. Moore, J. Am. Chem. Soc., 2015, 137, 10946-10949.

37 D. Marx and M. I. Menéndez, J. Org. Chem., 2018, 83, 2438-2441.

38 Y. Lin, C. C. Chang and S. L. Craig, Org. Chem. Front., 2019, 6, 1052-1057.

39 Y. Chen, A. J. H. Spiering, S. Karthikeyan, G. W. M. Peters, E. W. Meijer and R. P. Sijbesma, Nat. Chem., 2012, 4, 559562.

40 J. M. Clough and R. P. Sijbesma, ChemPhysChem, 2014, 15, 3565-3571.

41 J. Wang, T. B. Kouznetsova, Z. S. Kean, L. Fan, B. D. Mar, T. J. Martinez and S. L. Craig, J. Am. Chem. Soc., 2014, 136, 15162-15165.

42 Y. Chen and R. P. Sijbesma, Macromolecules, 2014, 47, 3797-3805.

43 E. Ducrot, Y. Chen, M. Bulters, R. P. Sijbesma and C. Creton, Science, 2014, 344, 186-189. 
44 J. M. Clough, A. Balan, T. L. J. van Daal and R. P. Sijbesma, Angew. Chem., Int. Ed., 2016, 55, 14451449.

45 J. M. Clough, J. van der Gucht and R. P. Sijbesma, Macromolecules, 2017, 50, 2043-2053.

46 V. N. Khiêm and M. Itskov, Int. J. Plast., 2018, 102, 1-15.

47 W. Yuan, Y. Yuan, F. Yang, M. Wu and Y. Chen, Macromolecules, 2018, 51, 9019-9026.

48 G. Kim, V. M. Lau, A. J. Halmes, M. L. Oelze, J. S. Moore and K. C. Li, Proc. Natl. Acad. Sci. U. S. A., 2019, 116, 10214-10222.

49 C. Yan, F. Yang, M. Wu, Y. Yuan, F. Chen and Y. Chen, Macromolecules, 2019, 52, 9376-9382.

50 Y. Yuan, M. Li, W. Yuan, F. Yang and Y. Chen, Macromol. Mater. Eng., 2019, 304, 1900056.

51 Y. Yuan, W. Chen, Z. Ma, Y. Deng, Y. Chen, Y. Chen and W. Hu, Chem. Sci., 2019, 10, 2206-2211.

52 E. M. Nofen, N. Zimmer, A. Dasgupta, R. Gunckel, B. Koo, A. Chattopadhyay and L. L. Dai, Polym. Chem., 2016, 7, 7249-7259.

53 H. Zhang, X. Li, Y. Lin, F. Gao, Z. Tang, P. Su, W. Zhang, Y. Xu, W. Weng and R. Boulatov, Nat. Commun., 2017, 8, 1147.

54 M. Li, H. Zhang, F. Gao, Z. Tang, D. Zeng, Y. Pan, P. Su, Y. Ruan, Y. Xu and W. Weng, Polym. Chem., 2019, 10, 905910.

55 J. Wang, T. B. Kouznetsova, R. Boulatov and S. L. Craig, Nat. Commun., 2016, 7, 13433.

56 Z. Chen, J. A. M. Mercer, X. Zhu, J. A. H. Romaniuk, R. Pfattner, L. Cegelski, T. J. Martinez, N. Z. Burns and Y. Xia, Science, 2017, 357, 475-479.

57 J. Yang, M. Horst, J. A. H. Romaniuk, Z. Jin, L. Cegelski and Y. Xia, J. Am. Chem. Soc., 2019, 141, 6479-6483.

58 J. K. Su, J. D. Feist, J. Yang, J. A. M. Mercer, J. A. H. Romaniuk, Z. Chen, L. Cegelski, N. Z. Burns and Y. Xia, J. Am. Chem. Soc., 2018, 140, 12388-12391.

59 Z. Chen, X. Zhu, J. Yang, J. A. M. Mercer, N. Z. Burns, T. J. Martinez and Y. Xia, Nat. Chem., 2020, DOI: 10.1038/ s41557-019-0396-5.

60 B. H. Bowser, C. H. Ho and S. L. Craig, Macromolecules, 2019, 52, 9032-9038.

61 Y. Lin, T. B. Kouznetsova and S. L. Craig, J. Am. Chem. Soc., 2020, 142, 2105-2109.

62 B. Rickborn, in Organic Reactions, ed. L. A. Paquette, John Wiley \& Sons, Inc., New York, 1987, vol. 52, pp. 1-393.

63 L. P. Engle and K. B. Wagener, J. Macromol. Sci., Rev. Macromol. Chem. Phys., 1993, C33, 239-257.

64 X. Chen, M. A. Dam, K. Ono, A. Mal, H. Shen, S. R. Nutt, K. Sheran and F. Wudl, Science, 2002, 295, 1698-1702.

65 N. Yoshie, M. Watanabe, H. Araki and K. Ishida, Polym. Degrad. Stab., 2010, 95, 826-829.

66 N. Yoshie, S. Saito and N. Oya, Polymer, 2011, 52, 60746079.

67 D. C. Church, G. I. Peterson and A. J. Boydston, ACS Macro Lett., 2014, 3, 648-651.
68 X. Hu, T. Zeng, C. C. Husic and M. J. Robb, J. Am. Chem. Soc., 2019, 141, 15018-15023.

69 G. I. Peterson, J. Lee and T. Choi, Macromolecules, 2019, 52, 9561-9568.

70 Y. Fang, J. Li, X. Du, Z. Du, X. Cheng and H. Wang, Polymer, 2018, 158, 166-175.

$71 \mathrm{~J}$. Li, B. Hu, K. Yang, B. Zhao and J. S. Moore, ACS Macro Lett., 2016, 5, 819-822.

72 J. Li, T. Shiraki, B. Hu, R. A. E. Wright, B. Zhao and J. S. Moore, J. Am. Chem. Soc., 2014, 136, 1592515928.

73 A. R. Sulkanen, J. Sung, M. J. Robb, J. S. Moore, N. R. Sottos and G. Y. Liu, J. Am. Chem. Soc., 2019, 141, 4080-4085.

74 H. Li, R. Göstl, M. Delgove, J. Sweeck, Q. Zhang, R. P. Sijbesma and J. P. A. Heuts, ACS Macro Lett., 2016, 5, 995-998.

75 H. Li, Y. Zhang, Y. Liu, R. P. Sijbesma, J. P. A. Heuts and Q. Zhang, Polym. Chem., 2017, 8, 3971-3976.

76 M. Stratigaki, C. Baumann, L. C. A. van Breemen, J. P. A. Heuts, R. P. Sijbesma and R. Göstl, Polym. Chem., 2020, 11, 358-366.

77 M. Zhang and G. De Bo, J. Am. Chem. Soc., 2018, 140, 12724-12727.

78 C. P. Kabb, C. S. O’Bryan, C. D. Morley, T. E. Angelini and B. S. Sumerlin, Chem. Sci., 2019, 10, 7702-7708.

79 H. Y. Duan, Y. X. Wang, L. J. Wang, Y. Q. Min, X. H. Zhang and B. Y. Du, Macromolecules, 2017, 50, 1353-1361.

80 B. Lyu, W. Cha, T. Mao, Y. Wu, H. Qian, Y. Zhou, X. Chen, S. Zhang, L. Liu, G. Yang, Z. Lu, Q. Zhu and H. Ma, ACS Appl. Mater. Interfaces, 2015, 7, 6254-6259.

81 J. Sung, M. J. Robb, S. R. White, J. S. Moore and N. R. Sottos, J. Am. Chem. Soc., 2018, 140, 5000-5003.

82 S. S. M. Konda, J. N. Brantley, B. T. Varghese, K. M. Wiggins, C. W. Bielawski and D. E. Makarov, J. Am. Chem. Soc., 2013, 135, 12722-12729.

83 R. Stevenson and G. De Bo, J. Am. Chem. Soc., 2017, 139, 16768-16771.

84 Z. Wang and S. L. Craig, Chem. Commun., 2019, 55, 12263-12266.

85 J. Kida, K. Imato, R. Goseki, D. Aoki, M. Morimoto and H. Otsuka, Nat. Commun., 2018, 9, 3504.

86 R. Göstl and S. Hecht, Angew. Chem., Int. Ed., 2014, 53, 8784-8787.

87 R. Göstl and S. Hecht, Chem. - Eur. J., 2015, 21, 44224427.

88 A. Fuhrmann, R. Göstl, R. Wendt, J. Kötteritzsch, M. D. Hager, U. S. Schubert, K. Brademann-Jock, A. F. Thünemann, U. Nöchel, M. Behl and S. Hecht, Nat. Commun., 2016, 7, 13623.

89 X. Hu, M. E. McFadden, R. W. Barber and M. J. Robb, J. Am. Chem. Soc., 2018, 140, 14073-14077.

90 R. Göstl and R. P. Sijbesma, Chem. Sci., 2016, 7, 370-375.

91 D. Yildiz, C. Baumann, A. Mikosch, A. J. C. Kuehne, A. Herrmann and R. Göstl, Angew. Chem., Int. Ed., 2019, 58, 12919-12923. 
92 M. B. Larsen and A. J. Boydston, J. Am. Chem. Soc., 2013, 135, 8189-8192.

93 M. B. Larsen and A. J. Boydston, J. Am. Chem. Soc., 2014, 136, 1276-1279.

94 B. Cao, N. Boechler and A. J. Boydston, Polymer, 2018, 152, 4-8.

95 R. Roessler and A. Zimmerman, J. Phys. Chem. C, 2018, 122, 6996-7004.

96 G. R. Gossweiler, G. B. Hewage, G. Soriano, Q. Wang, G. W. Welshofer, X. Zhao and S. L. Craig, ACS Macro Lett., 2014, 3, 216-219.

97 N. R. Sottos, Nat. Chem., 2014, 6, 381-383.

98 J. N. Brantley, K. M. Wiggins and C. W. Bielawski, Science, 2011, 333, 1606-1609.

99 M. McNutt, Editorial retraction, Science, 2015, 347, 834.

100 J. N. Brantley, S. S. M. Konda, D. E. Makarov and C. W. Bielawski, J. Am. Chem. Soc., 2012, 134, 9882-9885.

101 H. S. Smalø and E. Uggerud, Chem. Commun., 2012, 48, 10443-10445.

102 D. Schütze, K. Holz, J. Müller, M. K. Beyer, U. Lüning and B. Hartke, Angew. Chem., Int. Ed., 2015, 54, 2556-2559.

103 F. Li, C. Xie, Z. Cheng and H. Xia, Ultrason. Sonochem., 2016, 30, 9-17.

104 T. Stauch and A. Dreuw, Chem. Sci., 2017, 8, 5567-5575.

105 M. Krupička, P. Dopieralski and D. Marx, Angew. Chem., Int. Ed., 2017, 56, 7745-7749.

106 M. J. Jacobs, G. Schneider and K. G. Blank, Angew. Chem., Int. Ed., 2016, 55, 2899-2902.

107 A. Khanal, F. Long, B. Cao, R. Shahbazian-Yassar and S. Fang, Chem. - Eur. J., 2016, 22, 9760-9767.

108 H. Bouas-Laurent, A. Castellan, J.-P. Desvergne and R. Lapouyade, Chem. Soc. Rev., 2000, 29, 43-55.

109 P. Froimowicz, H. Frey and K. Landfester, Macromol. Rapid Commun., 2011, 32, 468-473.

110 Y. K. Song, K. H. Lee, W. S. Hong, S. Y. Cho, H. C. Yu and C. M. Chung, J. Mater. Chem., 2012, 22, 1380-1386.

111 S. R. Jezowski, L. Zhu, Y. Wang, A. P. Rice, G. W. Scott, C. J. Bardeen and E. L. Chronister, J. Am. Chem. Soc., 2012, 134, 7459-7466.

112 F. Tong, C. D. Cruz, S. R. Jezowski, X. Zhou, L. Zhu, R. O. Al-Kaysi, E. L. Chronister and C. J. Bardeen, J. Phys. Chem. A, 2014, 118, 5349-5354.

113 E. M. Nofen, J. Wickham, B. Koo, A. Chattopadhyay and L. L. Dai, Mater. Res. Express, 2016, 3, 035701.

114 E. M. Nofen, A. Dasgupta, N. Zimmer, R. Gunckel, B. Koo, A. Chattopadhyay and L. L. Dai, Polym. Eng. Sci., 2017, 57, 901-909.

115 L. Y. Hsu, S. Maity, Y. Matsunaga, Y. F. Hsu, Y. H. Liu, S. M. Peng, T. Shinmyozu and J. S. Yang, Chem. Sci., 2018, 9, 8990-9001.

116 B. Koo, J. Miller, R. Gunckel, A. Hall, L. Dai and A. Chattopadhyay, Smart Mater. Struct., 2019, 28, 115035.

117 L. Kan, H. Cheng, B. Li, X. Zhang, Q. Wang, H. Wei and N. Ma, New J. Chem., 2019, 43, 2658-2664.

118 T. Nishiuchi, S. Y. Uno, Y. Hirao and T. Kubo, J. Org. Chem., 2016, 81, 2106-2112.
119 B. Koo, E. Nofen, A. Chattopadhyay and L. Dai, Comput. Mater. Sci., 2017, 133, 167-174.

120 J. M. Lenhardt, A. L. Black and S. L. Craig, J. Am. Chem. Soc., 2009, 131, 10818-10819.

121 J. M. Lenhardt, M. T. Ong, R. Choe, C. R. Evenhuis, T. J. Martinez and S. L. Craig, Science, 2010, 329, 10571060.

122 D. Wu, J. M. Lenhardt, A. L. Black, B. B. Akhremitchev and S. L. Craig, J. Am. Chem. Soc., 2010, 132, 1593615938.

123 J. M. Lenhardt, J. W. Ogle, M. T. Ong, R. Choe, T. J. Martinez and S. L. Craig, J. Am. Chem. Soc., 2011, 133, 3222-3225.

124 J. M. Lenhardt, A. L. Black, B. A. Beiermann, B. D. Steinberg, F. Rahman, T. Samborski, J. Elsakr, J. S. Moore, N. R. Sottos and S. L. Craig, J. Mater. Chem., 2011, 21, 8454-8459.

125 A. L. Black Ramirez, J. W. Ogle, A. L. Schmitt, J. M. Lenhardt, M. P. Cashion, M. K. Mahanthappa and S. L. Craig, ACS Macro Lett., 2012, 1, 23-27.

126 H. M. Klukovich, T. B. Kouznetsova, Z. S. Kean, J. M. Lenhardt and S. L. Craig, Nat. Chem., 2013, 5, 110114.

127 A. L. B. Ramirez, Z. S. Kean, J. A. Orlicki, M. Champhekar, S. M. Elsakr, W. E. Krause and S. L. Craig, Nat. Chem., 2013, 5, 757-761.

128 A. L. Black Ramirez, A. K. Schmitt, M. K. Mahanthappa and S. L. Craig, Faraday Discuss., 2014, 170, 337-344.

129 Z. S. Kean, A. L. B. Ramirez and S. L. Craig, J. Polym. Sci., Part A: Polym. Chem., 2012, 50, 3481-3484.

130 B. Lee, Z. Niu and S. L. Craig, Angew. Chem., Int. Ed., 2016, 55, 13086-13089.

131 R. B. Woodward and R. Hoffmann, J. Am. Chem. Soc., 1965, 87, 395-397.

132 J. Wang, M. T. Ong, T. B. Kouznetsova, J. M. Lenhardt, T. J. Martinez and S. L. Craig, J. Org. Chem., 2015, 80, 11773-11778.

133 K. C. Neuman and A. Nagy, Nat. Methods, 2008, 5, 491505.

134 J. Wang, T. B. Kouznetsova, Z. Niu, M. T. Ong, H. M. Klukovich, A. L. Rheingold, T. J. Martinez and S. L. Craig, Nat. Chem., 2015, 7, 323-327.

135 J. Wang, T. B. Kouznetsova and S. L. Craig, J. Am. Chem. Soc., 2015, 137, 11554-11557.

136 J. Wang, T. B. Kouznetsova, Z. Niu, A. L. Rheingold and S. L. Craig, J. Org. Chem., 2015, 80, 11895-11898.

137 J. Wang, T. B. Kouznetsova and S. L. Craig, J. Am. Chem. Soc., 2016, 138, 10410-10412.

138 J. Ribas-Arino and D. Marx, Chem. Rev., 2012, 112, 54125487.

139 P. Dopieralski, J. Ribas-Arino and D. Marx, Angew. Chem., Int. Ed., 2011, 50, 7105-7108.

140 M. Wollenhaupt, M. Krupička and D. Marx, ChemPhysChem, 2015, 16, 1593-1597.

141 M. Wollenhaupt, C. Schran, M. Krupička and D. Marx, ChemPhysChem, 2018, 19, 837-847. 
142 A. L. Black, J. A. Orlicki and S. L. Craig, J. Mater. Chem., 2011, 21, 8460-8465.

143 J. M. Lenhardt, A. L. Black Ramirez, B. Lee, T. B. Kouznetsova and S. L. Craig, Macromolecules, 2015, 48, 6396-6403.

144 B. Lee, Z. Niu, J. Wang, C. Slebodnick and S. L. Craig, J. Am. Chem. Soc., 2015, 137, 10826-10832.

145 Y. Sha, Y. Zhang, E. Xu, Z. Wang, T. Zhu, S. L. Craig and C. Tang, ACS Macro Lett., 2018, 7, 1174-1179.

146 Y. Sha, Y. Zhang, E. Xu, C. W. McAlister, T. Zhu, S. L. Craig and C. Tang, Chem. Sci., 2019, 10, 4959-4965.

147 C. E. Diesendruck, B. D. Steinberg, N. Sugai, M. N. Silberstein, N. R. Sottos, S. R. White, P. V. Braun and J. S. Moore, J. Am. Chem. Soc., 2012, 134, 1244612449.

148 Y. Lin, T. B. Kouznetsova and S. L. Craig, J. Am. Chem. Soc., 2020, 142, 99-103.

149 G. Cravotto and P. Cintas, Angew. Chem., Int. Ed., 2007, 46, 5476-5478.

150 S. L. Potisek, D. A. Davis, N. R. Sottos, S. R. White and J. S. Moore, J. Am. Chem. Soc., 2007, 129, 13808-13809.

151 J. Wang, I. Piskun and S. L. Craig, ACS Macro Lett., 2015, 4, 834-837.

152 C. R. Hickenboth, J. S. Moore, S. R. White, N. R. Sottos, J. Baudry and S. R. Wilson, Nature, 2007, 446, 423-427.

153 I. Frank and J. Friedrichs, Nat. Chem., 2009, 1, 264-265.

154 K. M. Wiggins, J. N. Brantley and C. W. Bielawski, ACS Macro Lett., 2012, 1, 623-626.

155 T. B. Kouznetsova, J. Wang and S. L. Craig, ChemPhysChem, 2017, 18, 1486-1489.

156 M. T. Ong, J. Leiding, H. Tao, A. M. Virshup and T. J. Martinez, J. Am. Chem. Soc., 2009, 131, 6377-6379.

157 J. Ribas-Arino, M. Shiga and D. Marx, Chem. - Eur. J., 2009, 15, 13331-13335.

158 J. Ribas-Arino, M. Shiga and D. Marx, J. Am. Chem. Soc., 2010, 132, 10609-10614.

159 S. S. M. Konda, J. N. Brantley, C. W. Bielawski and D. E. Makarov, J. Chem. Phys., 2011, 135, 164103.

160 P. Dopieralski, P. Anjukandi, M. Rückert, M. Shiga, J. Ribas-Arino and D. Marx, J. Mater. Chem., 2011, 21, 8309-8316.

161 Y. Tian and R. Boulatov, Chem. Commun., 2013, 49, 41874189.

162 Y. Tian and R. Boulatov, ChemPhysChem, 2012, 13, 22772281.

163 L. Kortekaas and W. R. Browne, Chem. Soc. Rev., 2019, 48, 3406-3424.

164 R. Klajn, Chem. Soc. Rev., 2014, 43, 148-184.

165 D. S. Tipikin, Russ. J. Phys. Chem. A, 2001, 75, 1720-1722.

166 D. A. Davis, A. Hamilton, J. Yang, L. D. Cremar, D. Van Gough, S. L. Potisek, M. T. Ong, P. V. Braun, T. J. Martinez, S. R. White, J. S. Moore and N. R. Sottos, Nature, 2009, 459, 68-72.

167 B. A. Beiermann, S. L. B. Kramer, P. A. May, J. S. Moore, S. R. White and N. R. Sottos, Adv. Funct. Mater., 2014, 24, 1529-1537.
168 M. N. Silberstein, L. D. Cremar, B. A. Beiermann, S. B. Kramer, T. J. Martinez, S. R. White and N. R. Sottos, J. Mech. Phys. Solids, 2014, 63, 141-153.

169 P. A. May, N. F. Munaretto, M. B. Hamoy, M. J. Robb and J. S. Moore, ACS Macro Lett., 2016, 5, 177-180.

170 M. Li, Q. Zhang and S. Zhu, Polymer, 2016, 99, 521-528.

171 M. Li, L. Lei, Q. Zhang and S. Zhu, Macromol. Rapid Commun., 2016, 37, 957-962.

172 W. Qiu, P. A. Gurr and G. G. Qiao, ACS Appl. Mater. Interfaces, 2019, 11, 29268-29275.

173 Y. Zhang, B. Ren, F. Yang, Y. Cai, H. Chen, T. Wang, Z. Feng, J. Tang, J. Xu and J. Zheng, J. Mater. Chem. C, 2018, 6, 11536-11551.

174 B. A. Beiermann, D. A. Davis, S. L. B. Kramer, J. S. Moore, N. R. Sottos and S. R. White, J. Mater. Chem., 2011, 21, 8443-8447.

175 C. M. Kingsbury, P. A. May, D. A. Davis, S. R. White, J. S. Moore and N. R. Sottos, J. Mater. Chem., 2011, 21, 8381-8388.

176 C. M. Degen, P. A. May, J. S. Moore, S. R. White and N. R. Sottos, Macromolecules, 2013, 46, 8917-8921.

177 M. N. Silberstein, K. Min, L. D. Cremar, C. M. Degen, T. J. Martinez, N. R. Aluru, S. R. White and N. R. Sottos, J. Appl. Phys., 2013, 114, 023504.

178 J. R. Hemmer, P. D. Smith, M. Van Horn, S. Alnemrat, B. P. Mason, J. R. De Alaniz, S. Osswald and J. P. Hooper, J. Polym. Sci., Part B: Polym. Phys., 2014, 52, 13471356.

179 C. K. Lee, C. E. Diesendruck, E. Lu, A. N. Pickett, P. A. May, J. S. Moore and P. V. Braun, Macromolecules, 2014, 47, 2690-2694.

180 A. D. N. Celestine, B. A. Beiermann, P. A. May, J. S. Moore, N. R. Sottos and S. R. White, Polymer, 2014, 55, 41644171.

181 J. W. Kim, Y. Jung, G. W. Coates and M. N. Silberstein, Macromolecules, 2015, 48, 1335-1342.

182 G. Kister, M. Moniruzzaman, M. Khan and S. Debnath, Dyes Pigm., 2019, 162, 309-314.

183 J. Y. Jo, H. G. Jang, Y. C. Jung, D. C. Lee and J. Kim, ACS Macro Lett., 2019, 8, 882-887.

184 A. D. N. Celestine, N. R. Sottos and S. R. White, Strain, 2019, 55, 1-17.

185 S. R. White, C. K. Lee, N. R. Sottos, D. A. Davis, P. V. Braun and J. S. Moore, J. Am. Chem. Soc., 2010, 132, 16107-16111.

186 C. K. Lee, B. A. Beiermann, M. N. Silberstein, J. Wang, J. S. Moore, N. R. Sottos and P. V. Braun, Macromolecules, 2013, 46, 3746-3752.

187 T. A. Kim, B. A. Beiermann, S. R. White and N. R. Sottos, ACS Macro Lett., 2016, 5, 1312-1316.

188 G. Hong, H. Zhang, Y. Lin, Y. Chen, Y. Xu, W. Weng and H. Xia, Macromolecules, 2013, 46, 8649-8656.

189 X. Fang, H. Zhang, Y. Chen, Y. Lin, Y. Xu and W. Weng, Macromolecules, 2013, 46, 6566-6574.

190 H. Zhang, Y. Chen, Y. Lin, X. Fang, Y. Xu, Y. Ruan and W. Weng, Macromolecules, 2014, 47, 6783-6790. 
191 Y. Chen, H. Zhang, X. Fang, Y. Lin, Y. Xu and W. Weng, ACS Macro Lett., 2014, 3, 141-145.

192 Q. Zhang, Y. Wang, C. Xing, Y. Cai, K. Xi and X. Jia, $R S C$ Adv., 2017, 7, 12682-12689.

193 C. Xing, L. Wang, L. Xian, Y. Wang, L. Zhang, K. Xi, Q. Zhang and X. Jia, Macromol. Chem. Phys., 2018, 219, 1800042.

194 G. R. Gossweiler, C. L. Brown, G. B. Hewage, E. Sapiro-Gheiler, W. J. Trautman, G. W. Welshofer and S. L. Craig, ACS Appl. Mater. Interfaces, 2015, 7, 2243122435.

195 S. Cho, S. Kang, A. Pandya, R. Shanker, Z. Khan, Y. Lee, J. Park, S. L. Craig and H. Ko, ACS Nano, 2017, 11, 43464357.

196 C. L. Brown, M. H. Barbee, J. H. Ko, H. D. Maynard and S. L. Craig, J. Chem. Educ., 2017, 94, 1752-1755.

197 R. C. Rohde, A. Basu, L. B. Okello, M. H. Barbee, Y. Zhang, O. D. Velev, A. Nelson and S. L. Craig, Polym. Chem., 2019, 10, 5985-5991.

198 J. Park, Y. Lee, M. H. Barbee, S. Cho, S. Cho, R. Shanker, J. Kim, J. Myoung, M. P. Kim, C. Baig, S. L. Craig and H. Ko, Adv. Mater., 2019, 31, 1-10.

199 Z. Xia, V. D. Alphonse, D. B. Trigg, T. P. Harrigan, J. M. Paulson, Q. T. Luong, E. P. Lloyd, M. H. Barbee and S. L. Craig, Molecules, 2019, 24, 542.

200 M. H. Barbee, K. Mondal, J. Z. Deng, V. Bharambe, T. V. Neumann, J. J. Adams, N. Boechler, M. D. Dickey and S. L. Craig, ACS Appl. Mater. Interfaces, 2018, 10, 2991829924.

201 Q. Wang, G. R. Gossweiler, S. L. Craig and X. Zhao, Nat. Commun., 2014, 5, 4899.

202 Q. Wang, G. R. Gossweiler, S. L. Craig and X. Zhao, J. Mech. Phys. Solids, 2015, 82, 320-344.

203 M. E. Grady, B. A. Beiermann, J. S. Moore and N. R. Sottos, ACS Appl. Mater. Interfaces, 2014, 6, 53505355.

204 G. O’Bryan, B. M. Wong and J. R. McElhanon, ACS Appl. Mater. Interfaces, 2010, 2, 1594-1600.

205 N. Yenpech, V. Intasanta, K. Tashiro and S. Chirachanchai, Polym. Chem., 2020, 11, 91-101.

206 M. Li, W. Liu and S. Zhu, Polymer, 2017, 112, 219-227.

207 Y. Vidavsky, S. J. Yang, B. A. Abel, I. Agami, C. E. Diesendruck, G. W. Coates and M. N. Silberstein, J. Am. Chem. Soc., 2019, 141, 10060-10067.

208 F. Kempe, O. Brügner, H. Buchheit, S. N. Momm, F. Riehle, S. Hameury, M. Walter and M. Sommer, Angew. Chem., Int. Ed., 2018, 57, 997-1000.

209 L. J. Wang, X. J. Zhou, X. H. Zhang and B. Y. Du, Macromolecules, 2016, 49, 98-104.

210 H. Chen, F. Yang, Q. Chen and J. Zheng, Adv. Mater., 2017, 29, 1606900.

211 Y. Jia, W. J. Wang, B. G. Li and S. Zhu, Macromol. Mater. Eng., 2018, 303, 1800154.
212 S. Jiang, L. Zhang, T. Xie, Y. Lin, H. Zhang, Y. Xu, W. Weng and L. Dai, ACS Macro Lett., 2013, 2, 705-709.

213 M. Li, W. Liu, Q. Zhang and S. Zhu, ACS Appl. Mater. Interfaces, 2017, 9, 15156-15163.

214 Y. Jia, S. Wang, W. J. Wang, B. G. Li and S. Zhu, Macromolecules, 2019, 52, 7920-7928.

215 M. Raisch, D. Genovese, N. Zaccheroni, S. B. Schmidt, M. L. Focarete, M. Sommer and C. Gualandi, Adv. Mater., 2018, 30, 1802813.

216 M. Takaffoli, T. Zhang, D. Parks and X. Zhao, J. Appl. Mech., 2016, 83, 071007.

217 G. I. Peterson, M. B. Larsen, M. A. Ganter, D. W. Storti and A. J. Boydston, ACS Appl. Mater. Interfaces, 2015, 7, 577-583.

218 G. R. Gossweiler, T. B. Kouznetsova and S. L. Craig, J. Am. Chem. Soc., 2015, 137, 6148-6151.

219 T. A. Kim, M. J. Robb, J. S. Moore, S. R. White and N. R. Sottos, Macromolecules, 2018, 51, 9177-9183.

220 W. Qiu, P. A. Gurr, G. Da Silva and G. G. Qiao, Polym. Chem., 2019, 10, 1650-1659.

221 Y. Lin, M. H. Barbee, C. C. Chang and S. L. Craig, J. Am. Chem. Soc., 2018, 140, 15969-15975.

222 M. H. Barbee, T. Kouznetsova, S. L. Barrett, G. R. Gossweiler, Y. Lin, S. K. Rastogi, W. J. Brittain and S. L. Craig, J. Am. Chem. Soc., 2018, 140, 12746-12750.

223 V. I. Minkin, Chem. Rev., 2004, 104, 2751-2776.

224 Y. Shiraishi, K. Tanaka, E. Shirakawa, Y. Sugano, S. Ichikawa, S. Tanaka and T. Hirai, Angew. Chem., Int. Ed., 2013, 52, 8304-8308.

225 H. Zhang, F. Gao, X. Cao, Y. Li, Y. Xu, W. Weng and R. Boulatov, Angew. Chem., Int. Ed., 2016, 55, 3040-3044.

226 M. J. Robb, T. A. Kim, A. J. Halmes, S. R. White, N. R. Sottos and J. S. Moore, J. Am. Chem. Soc., 2016, 138, 12328-12331.

227 T. Kosuge, X. Zhu, V. M. Lau, D. Aoki, T. J. Martinez, J. S. Moore and H. Otsuka, J. Am. Chem. Soc., 2019, 141, 1898-1902.

228 M. E. McFadden and M. J. Robb, J. Am. Chem. Soc., 2019, 141, 11388-11392.

229 H. N. Kim, M. H. Lee, H. J. Kim, J. S. Kim and J. Yoon, Chem. Soc. Rev., 2008, 37, 1465-1472.

230 M. J. Teng, X. R. Jia, X. F. Chen and Y. Wei, Angew. Chem., Int. Ed., 2012, 51, 6398-6401.

231 Z. Ma, M. Teng, Z. Wang, S. Yang and X. Jia, Angew. Chem., Int. Ed., 2013, 52, 12268-12272.

232 Z. Wang, Z. Ma, Y. Wang, Z. Xu, Y. Luo, Y. Wei and X. Jia, Adv. Mater., 2015, 27, 6469-6474.

233 L. Wang, W. Zhou, Q. Tang, H. Yang, Q. Zhou and X. Zhang, Polymers, 2018, 10, 994.

234 T. Wang, N. Zhang, J. Dai, Z. Li, W. Bai and R. Bai, ACS Appl. Mater. Interfaces, 2017, 9, 11874-11881.

235 L. J. Wang, K. X. Yang, Q. Zhou, H. Y. Yang, J. Q. He and X. Y. Zhang, Chin. J. Polym. Sci., 2019, 38, 24-36. 